\title{
Why do psychiatric patients stop antipsychotic medication? A systematic review of reasons for nonadherence to medication in patients with serious mental illness
}

\author{
This article was published in the following Dove Press journal: \\ Patient Preference and Adherence \\ 3 March 2017 \\ Number of times this article has been viewed
}

\author{
Dawn I Velligan' \\ Martha Sajatovic ${ }^{2}$ \\ Ainslie Hatch ${ }^{3}$ \\ Pavel Kramata ${ }^{4}$ \\ John P Docherty ${ }^{3}$ \\ 'Department of Psychiatry, \\ The University of Texas Health \\ Science Center, San Antonio, TX, \\ ${ }^{2}$ Departments of Psychiatry and \\ Neurology, Case Western Reserve \\ University School of Medicine, \\ Cleveland, OH, ${ }^{3}$ Medical Affairs, ODH, \\ Inc., Princeton, NJ, ${ }^{4} \mathrm{C} 4$ MedSolutions \\ LLC, Yardley, PA, USA
}

\begin{abstract}
Background: Antipsychotic medication reduces the severity of serious mental illness (SMI) and improves patient outcomes only when medicines were taken as prescribed. Nonadherence to the treatment of SMI increases the risk of relapse and hospitalization and reduces the quality of life. It is necessary to understand the factors influencing nonadherence to medication in order to identify appropriate interventions. This systematic review assessed the published evidence on modifiable reasons for nonadherence to antipsychotic medication in patients with SMI.
\end{abstract}

Methods: Articles published between January 1, 2005, and September 10, 2015, were searched on MEDLINE through PubMed. Abstracts were independently screened by 2 randomly assigned authors for inclusion, and disagreement was resolved by another author. Selected full-text articles were divided among all authors for review.

Results: A qualitative analysis of data from 36 articles identified 11 categories of reasons for nonadherence. Poor insight was identified as a reason for nonadherence in 55.6\% (20/36) of studies, followed by substance abuse $(36.1 \%, 13 / 36)$, a negative attitude toward medication (30.5\%, 11/36), medication side effects $(27.8 \%, 10 / 36)$, and cognitive impairments $(13.4 \%$, $7 / 36)$. A key reason directly associated with intentional nonadherence was a negative attitude toward medication, a mediator of effects of insight and therapeutic alliance. Substance abuse was the only reason consistently associated with unintentional nonadherence, regardless of type and stage of SMI.

Discussion: Although adherence research is inherently biased because of numerous methodological limitations and specific reasons under investigation, reasons for nonadherence consistently identified as significant across studies likely reflect valid existing associations with important clinical implications.

Conclusion: This systematic review suggests that a negative attitude toward medication and substance abuse are consistent reasons for nonadherence to antipsychotic medication among people with SMI. Adherence enhancement approaches that specifically target these reasons may improve adherence in a high-risk group. However, it is also important to identify drivers of poor adherence specific to each patient in selecting and implementing intervention strategies.

Keywords: adherence, antipsychotics, attitude toward medication, bipolar disorder, schizophrenia, substance abuse

\section{Introduction}

Antipsychotic medication reduces the severity of serious mental illness (SMI) and improves patient outcomes. A meta-analysis of 65 clinical trials in patients with 
schizophrenia stabilized on antipsychotic medication who were randomized to continue the treatment or switch to placebo showed that treatment with antipsychotics significantly reduces rates of relapse. ${ }^{1}$ A meta-analysis of 6 placebocontrolled randomized clinical trials in patients with acute schizophrenia treated with antipsychotics demonstrated a significant improvement in positive and negative symptoms over 6 weeks, with proportionately increasing treatment effect in those with more severe symptoms at baseline. ${ }^{2}$ A meta-analysis of 12 randomized clinical trials assessing acute mania (in bipolar disorder) showed that antipsychotic monotherapy significantly improved mania symptoms compared with placebo. ${ }^{3}$ However, medication is effective only when it is actually ingested, and nonadherence is a major impediment to effective treatment in patients with SMI. It should be noted that atypical antipsychotic drugs are currently only approved as adjunctive therapy for patients with major depressive disorder (MDD). ${ }^{4-6}$

Rates of partial adherence or nonadherence with foundational psychopharmacologic treatments in SMI vary but are estimated to be at least $40 \%-50 \%{ }^{7.8}$ In addition, it is difficult to maintain adherence over time (often referred to as persistence), and rates of nonadherence further worsen with longer observation periods. For example, a 4-year retrospective, cross-sectional study from a large cohort of patients with schizophrenia from the US Department of Veterans Affairs found that $\sim 36 \%$ of patients were poorly adherent in each year and that $61 \%$ had adherence problems at some point during the 4-year period. ${ }^{9}$

Ongoing adherence to antipsychotics is critical for optimal outcomes in patients with SMI. Interruption of treatment as short as 1-10 days has been associated with an increased risk of hospitalization in patients with schizophrenia. ${ }^{10}$ In addition to hospitalization, medication nonadherence has been associated with an increased use of emergency psychiatric services, violence, arrests, an increased risk of suicide attempt, poor social and occupational functioning, and reduced quality of life. ${ }^{11-13}$ Interventions to improve adherence have the potential to reduce these risks, but it seems unlikely that a "one size fits all" approach to enhance adherence with foundational medications is appropriate for all or even most patients with SMI. To develop and deliver person-centered care that is evidence-based and tailored to address specific adherence problems, ${ }^{14}$ it is necessary to identify and understand the most common and potentially modifiable reasons influencing medication nonadherence. For example, for a patient with both poor insight into disease and poor attitude toward medication, cognitive behavioral therapy would be a more suitable treatment than a long-acting injectable antipsychotic.
A psychosocial intervention customized by identified reasons for nonadherence (customized adherence enhancement) has demonstrated improvement in adherence, symptoms, and functioning of patients with bipolar disorder. ${ }^{15}$

Although people with SMI often receive various psychotropic medications, antipsychotic drugs are a common therapeutic strategy in a number of chronic psychiatric conditions, including schizophrenia, schizoaffective disorder, and bipolar disorder, and are used as adjunctive treatment to antidepressants in major depression. This systematic review assessed the published evidence related to each individual potentially modifiable reason affecting adherence to antipsychotic medication in patients with SMI, including schizophrenia, bipolar disorder, and MDD.

\section{Methods}

\section{Information source and eligibility criteria}

This review was conducted on the basis of recommendations outlined by the Preferred Reporting Items for Systematic Reviews and Meta-Analyses statement. ${ }^{16}$ English-language articles published between January 1, 2005, and September 10, 2015, in peer-reviewed journals were searched on MEDLINE through PubMed using the following string of key terms: (MDD OR "major depressive disorder" OR schizophrenia OR "bipolar disorder") AND ("adherence" OR "nonadherence" OR "non-adherence" OR "compliance" OR "noncompliance" OR "non-compliance") AND ("risk" OR "reason") AND English [Language] AND ("2005/01/01" [Date - Publication]: "3000” [Date Publication]) NOT review (ptyp). Eligible studies reported at least 1 potentially modifiable risk factor/reason for adherence or nonadherence to prescribed antipsychotic medication in patients with schizophrenia, bipolar disorder, or MDD identified during clinical interaction (ie, reasons that were reported by the patient, health care professional [HCP], or family). HCPs included physicians and case managers. Studies reporting only nonmodifiable reasons (eg, sociodemographic characteristics) were excluded. Modifiable reasons include those that can potentially be addressed clinically or through psychosocial intervention, whereas nonmodifiable reasons are those considered to be inherent to the individual (eg, age, sex, and ethnicity). Review articles, editorials, and articles reporting results from method development, such as psychometric properties of an instrument, were also excluded.

\section{Article selection process}

The title and abstract of each retrieved article were independently screened by 2 randomly assigned authors. Instances 
of disagreement about inclusion was resolved by a third author. Selected full-text articles were divided among all authors for detailed review and assessed for inclusion based on predefined eligibility criteria. Figure 1 shows the process of article selection.

\section{Results}

\section{Article selection}

A total of 545 articles were retrieved through the search; 458 articles were excluded following screening of titles and abstracts, and 87 articles were selected for a full-text review. Screening of references from 2 published reviews on medication adherence/nonadherence in schizophreniaspectrum disorders ${ }^{17,18}$ found 9 potentially relevant articles not identified by the search (missing the term "risk" or "reason" in title/abstract); the full text of these articles was also reviewed. Thirty-six articles met the eligibility criteria and were included in the qualitative data analysis (Figure 1).

\section{Characteristics of selected studies}

Nineteen studies of the final selected reports were cross-sectional $(52.8 \%, 19 / 36)$, including 3 surveys; 11 were prospective observational studies or clinical trials $(30.6 \%$, $11 / 36$ ); and 6 were post hoc analyses of data from prospective studies or clinical trials $(16.7 \%, 6 / 36)$. A brief summary of results from each of the studies is provided in Tables 1 and $2^{12,19-34}$ (prospective and post hoc analyses) and Tables 3 and $4^{35-53}$ (cross-sectional). Most of the studies were conducted in patients with schizophrenia or schizophrenia-like disorders $(75 \%, 27 / 36)$. An additional 3 studies were conducted in patients with schizophrenia or bipolar disorder, 4 in patients with bipolar disorder, and 2 in patients with SMI that also included MDD. Studies from Europe, the United States, or Canada comprised 75\% (27/36) of the group. An additional 4 studies were from Asia, 3 from Africa, and 1 each from Australia and Israel. Most of the studies (88.9\%, 32/36) were published between 2006 and 2013, with a range of 3-6 studies published each year during that period. Insight was the most frequently investigated reason for nonadherence, reported in $55.6 \%(20 / 36)$ of the studies, followed by substance abuse $(36.1 \%, 13 / 36)$, attitude toward medication $(30.5 \%, 11 / 36)$, medication side effects $(27.8 \%, 10 / 36)$, and cognitive impairments (19.4\%, 7/36; Figure 212,19,20,22-36,38-50,52-55).

\section{Findings from individual studies}

The identified reasons for nonadherence were divided into 2 groups (intentional and unintentional), reflecting the contrast between personal choice of patients and objective barriers to taking medication. Defining reasons in this way may be useful for identifying or developing appropriate adherence enhancement intervention strategies.

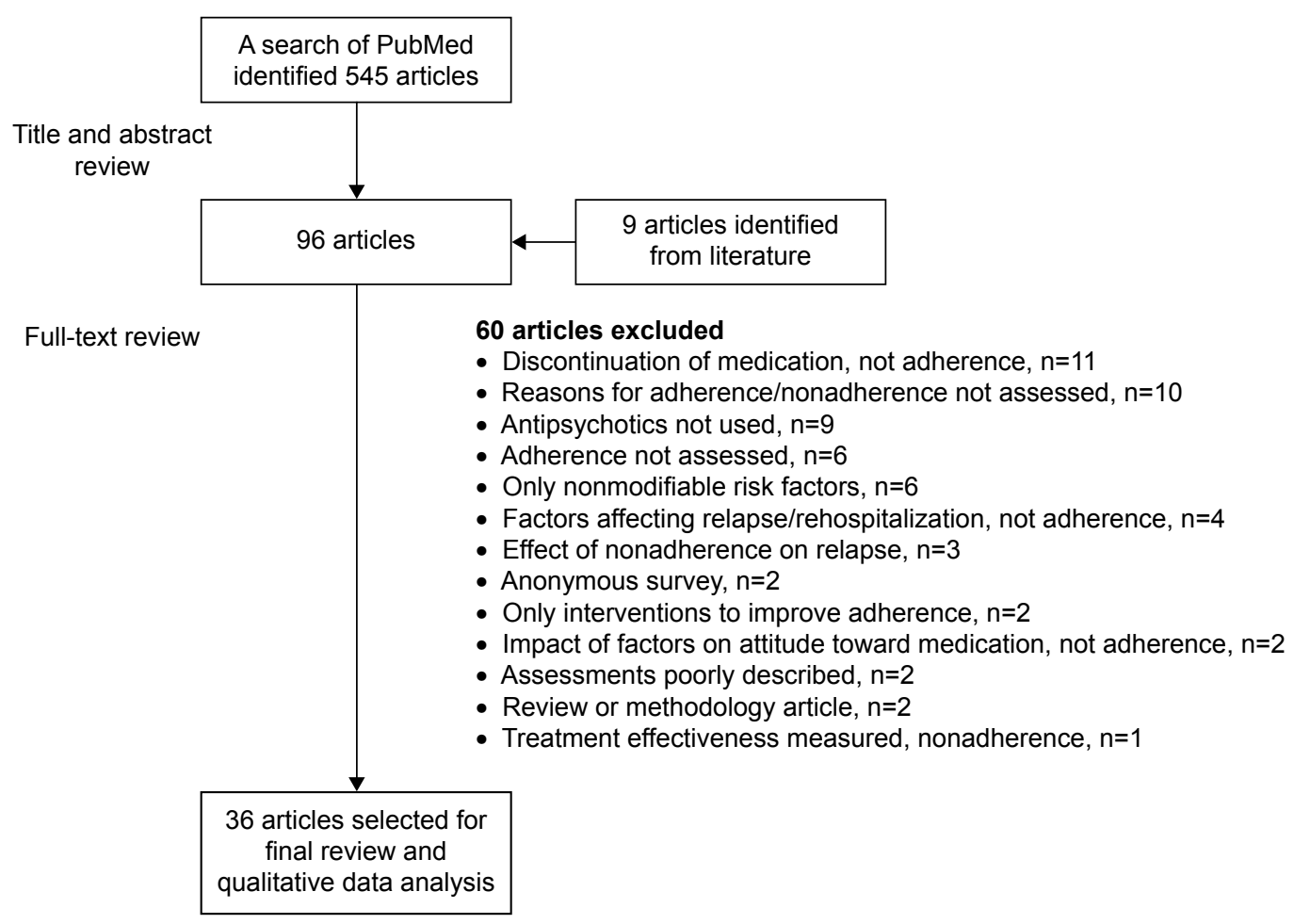

Figure I Flow schema of study selection process. 


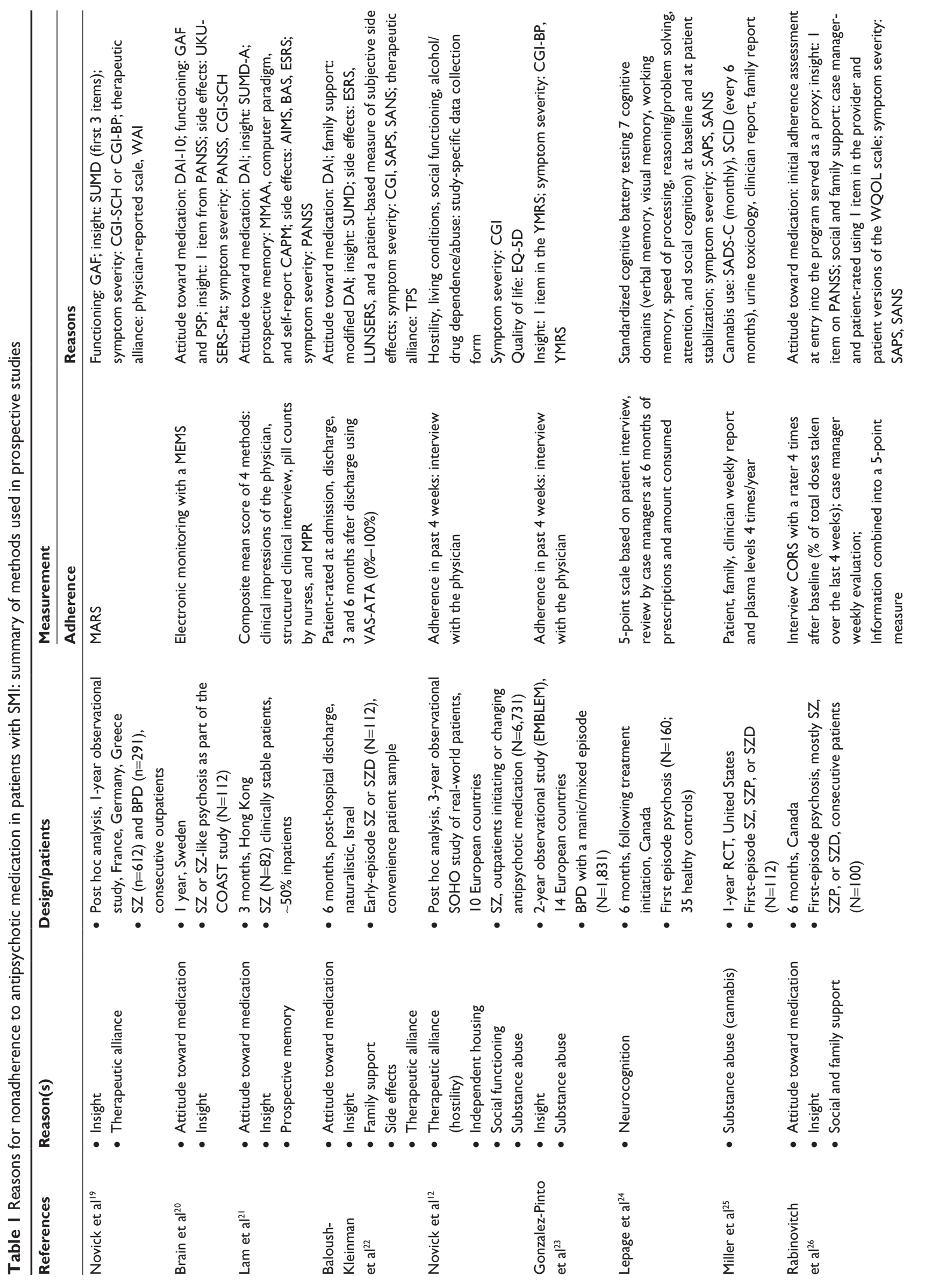



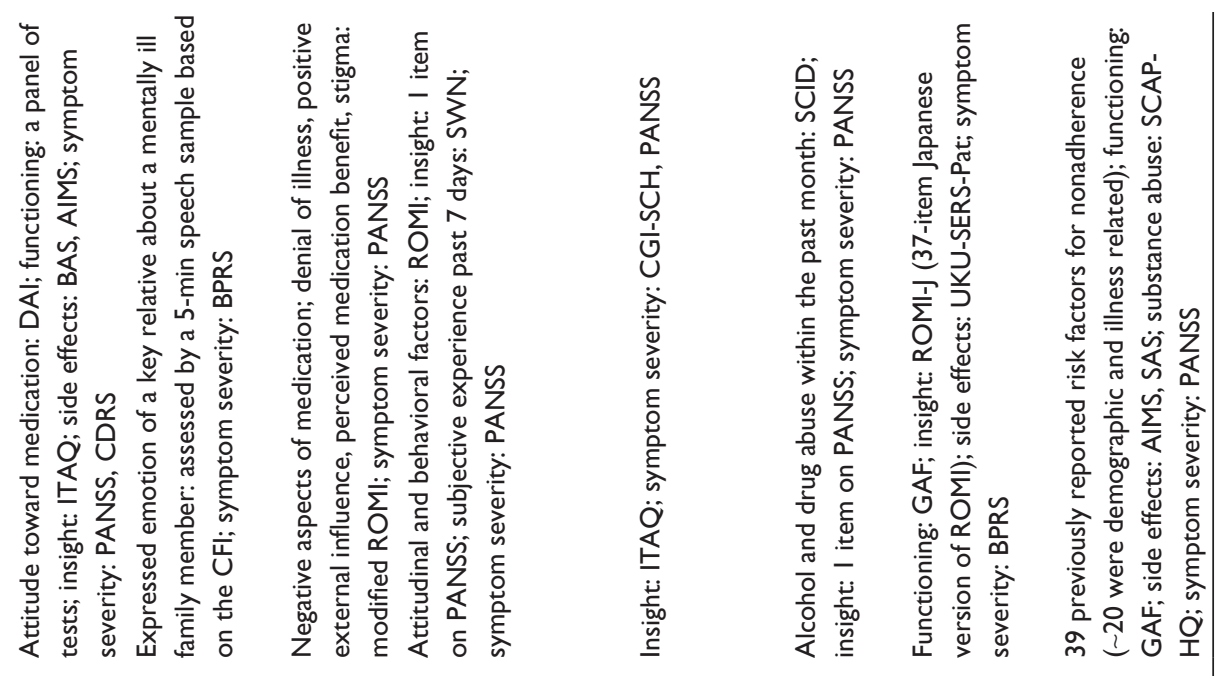

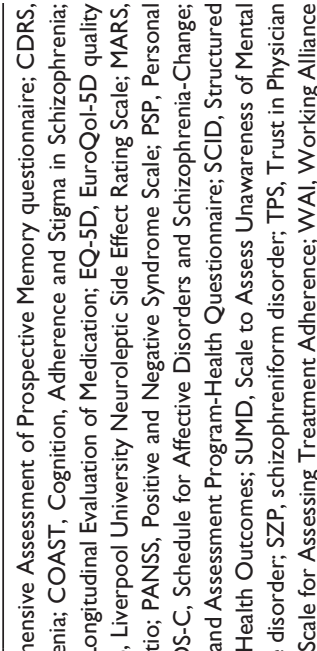

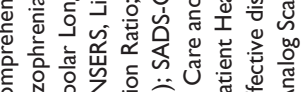
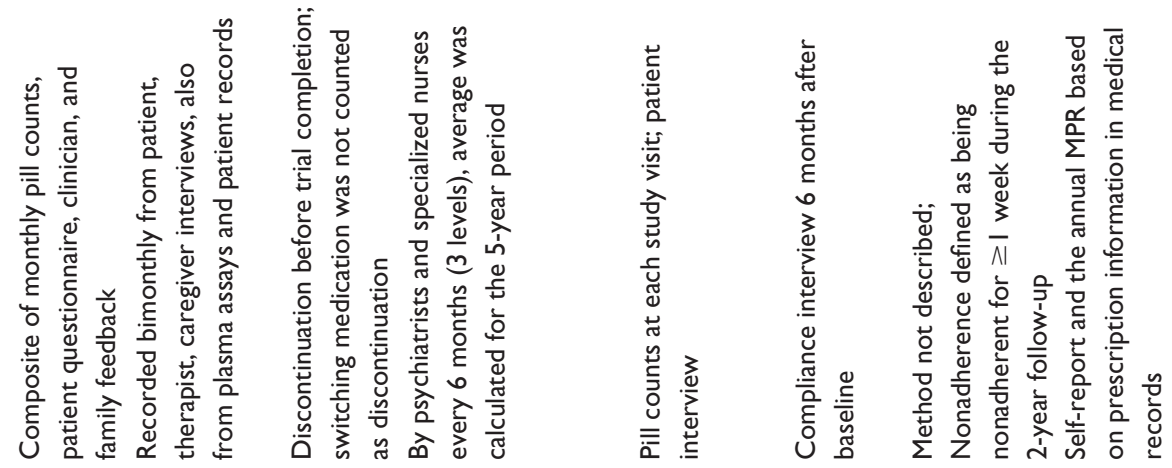

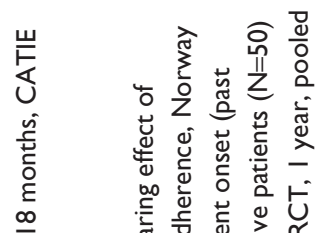
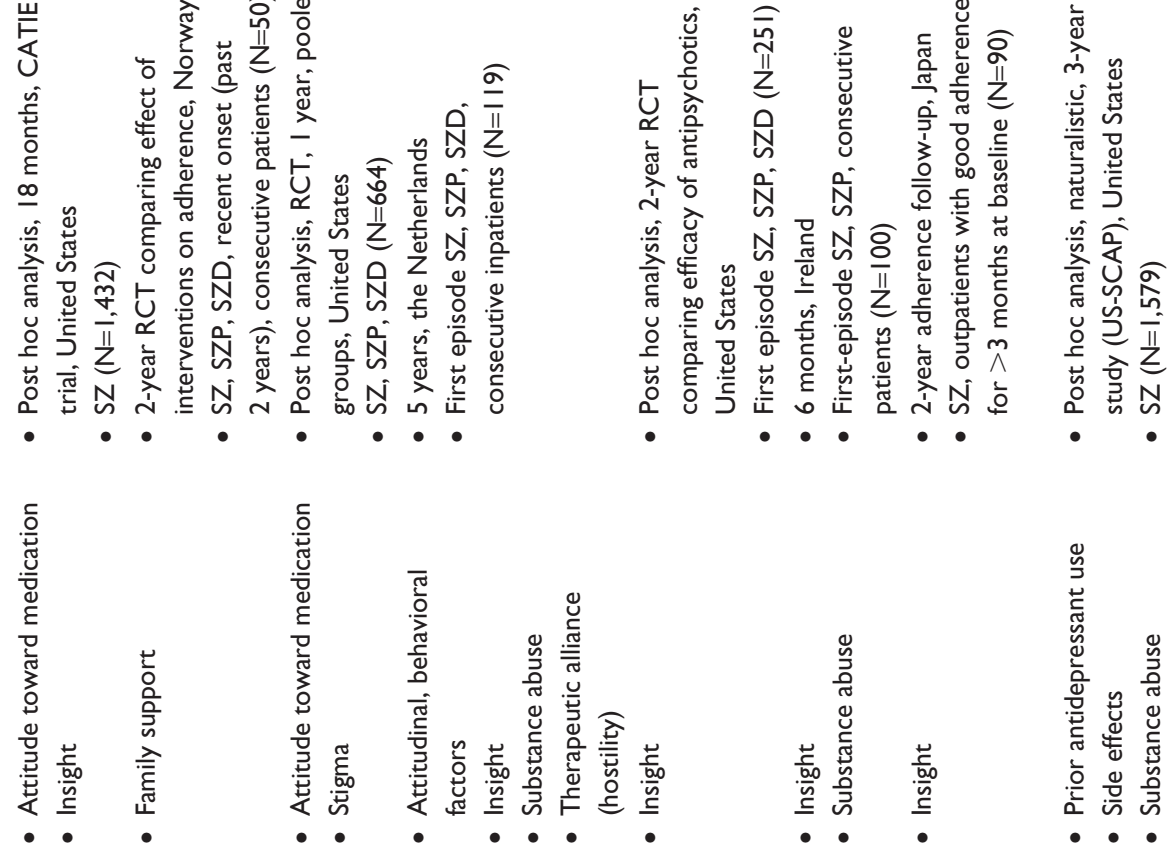

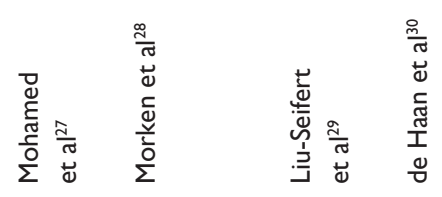

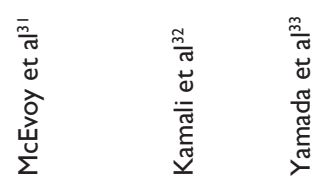

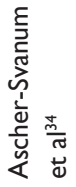

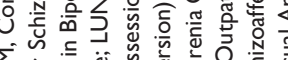

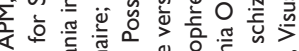
Uु

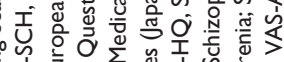

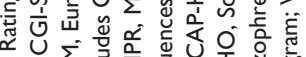

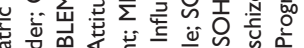

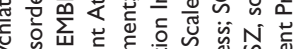

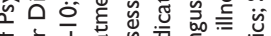

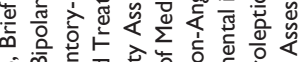
vi

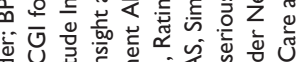

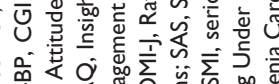

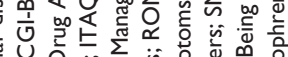

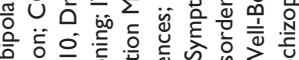

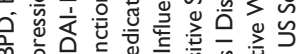
记

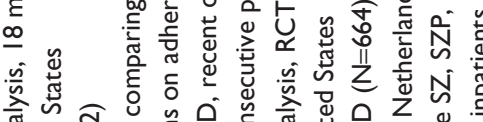

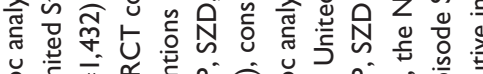

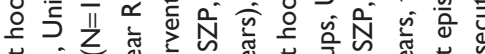

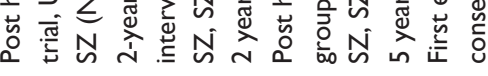


Table 2 Reasons for nonadherence to antipsychotic medication in patients with SMI: results of prospective studies

\begin{tabular}{|c|c|}
\hline References & Results \\
\hline Novick et al ${ }^{19}$ & $\begin{array}{l}\text { - Higher baseline insight and therapeutic alliance were associated with better adherence (each } P<0.000 \mathrm{I} \text { ) } \\
\text { - After I year of follow-up, significant direct associations were found between an improvement in the patient's } \\
\text { insight or an improvement in the patient-physician relationship and improved medication adherence } \\
\text { - Insight and therapeutic alliance co-vary during the course of the disorder and bidirectionally affect each other }\end{array}$ \\
\hline Brain et $\mathrm{al}^{20}$ & $\begin{array}{l}\text { - Nonadherence rate was } 27 \%(\leq 80 \% \mathrm{MEMS} \text { adherence) } \\
\text { - Negative drug attitude }(\mathrm{OR}=0.7 \mathrm{I}, P<0.00 \mathrm{I}) \text { and worse psychosocial function }(\mathrm{OR}=0.94, P=0.007) \text { were } \\
\text { significant predictors of nonadherence in a multivariable model } \\
\text { - Poor insight into illness was a significant predictor of nonadherence }(\mathrm{OR}=\mathrm{I.6I}, 95 \% \mathrm{Cl}: \mathrm{I.08-2.42}) \text { in a univariable } \\
\text { model but was not included in the best-fitting multivariable model }\end{array}$ \\
\hline Lam et $\mathrm{al}^{2 !}$ & $\begin{array}{l}\text { - } 33 \% \text { of patients were nonadherent ( }<80 \% \text { on composite score) } \\
\text { - At } 3 \text { months, nonadherent patients had significantly worse prospective memory, symptom severity, insight, and } \\
\text { attitude toward medication } \\
\text { - Poor insight }(O R=1.26, P=0.03) \text { and worse symptom severity }(O R=1.94, P=0.03) \text { were significant predictors of } \\
\text { nonadherence at } 3 \text { months } \\
\text { - Prospective memory moderated adherence-predictive effects of insight and psychopathology but was not an } \\
\text { independent predictor in a regression model } \\
\text { - Prospective memory accounted for only a small proportion of the variance of nonadherence; medication } \\
\text { management ability was a better predictor of nonadherence than prospective memory }\end{array}$ \\
\hline Baloush-Kleinman et $\mathrm{al}^{22}$ & $\begin{array}{l}\text { - Compared with non/partially adherent patients, adherent patients showed better attitude toward medication } \\
(P<0.000 \mathrm{I}) \text {, higher levels of insight into illness }(P=0.009) \text { and awareness of need for treatment }(P=0.0003) \text {, better } \\
\text { therapeutic alliance }(P=0.012) \text {, greater family involvement in treatment }(P=0.000 \mathrm{I}) \text {, more positive attitudes toward } \\
\text { medication in family }(P<0.000 \mathrm{I}) \text {, and greater severity of side effects }(P=0.036) \\
\text { - In a model predicting adherence at } 6 \text { months, attitudes toward medication mediated the effects of negative } \\
\text { symptoms, awareness of the illness, and awareness of the need for medication adherence }\end{array}$ \\
\hline Novick et al ${ }^{12}$ & $\begin{array}{l}\text { - } 28.8 \% \text { of patients were nonadherent ( } \leq 50 \% \text { of doses taken) during the } 3 \text {-year follow-up } \\
\text { - Prior adherence was the best predictor of adherence during follow-up }(O R=4.0 \mathrm{I}, P<0.00 \mathrm{I}) \\
\text { - Baseline predictors of nonadherence (logistic regression): alcohol dependence }(\mathrm{OR}=0.63, P=0.0 \mathrm{I} 3) \text { and substance } \\
\text { abuse }(O R=0.67, P=0.043) \text { in the previous month, independent housing }(O R=0.8, P=0.00 \mathrm{I}) \text {, presence of hostility } \\
(\mathrm{OR}=0.85, P=0.02) \\
\text { - Good social functioning was a predictor of adherence }(O R=I .26, P<0.00 \mathrm{I})\end{array}$ \\
\hline Gonzalez-Pinto et $\mathrm{a}^{23}$ & $\begin{array}{l}\text { - 23.4\% of patients were nonadherent (answered "adherent about half of the time or almost never adherent" at } \geq 1 \\
\text { interview during maintenance phase) } \\
\text { - During maintenance, patients were more likely to be adherent if they had good insight (OR }=1.98,95 \% \\
\mathrm{Cl}: \text { I.44-2.72; } P<0.00 \mathrm{I}) \text { and less likely to be adherent if they used cannabis during the treatment (OR }=0.31,95 \% \\
\mathrm{Cl}: 0.18-0.54 ; P<0.00 \mathrm{I}) \text { and had greater disease severity ( } \mathrm{OR}=0.9 \mathrm{I}, 95 \% \mathrm{Cl}: 0.84-0.99 ; P=0.028)\end{array}$ \\
\hline Lepage et $\mathrm{al}^{24}$ & $\begin{array}{l}\text { - } 62 \%, 17 \% \text {, and } 21 \% \text { of patients were fully ( }>75 \% \text { of doses taken), partially }(51 \%-75 \%) \text {, and poorly adherent } \\
(\leq 50 \%) \text {, respectively } \\
\text { - No significant associations were observed between global or domain-specific cognitive performance and } \\
\text { adherence at } 6 \text { months }\end{array}$ \\
\hline Miller et $\mathrm{a}^{25}$ & $\begin{array}{l}\text { - I8\% of patients were nonadherent at the end of the study }(<50 \% \text { of the dose) } \\
\text { - } 15 \%-20 \% \text { of patients used cannabis } \\
\text { - Patients who used cannabis were } 2.4 \text {-fold }(95 \% \mathrm{Cl}: 1.5-3.9) \text { more likely to be nonadherent and } 6.4 \text {-fold }(95 \% \\
\text { Cl: } 1.2-35.6) \text { more likely to drop out of the study }\end{array}$ \\
\hline Rabinovitch et $\mathrm{al}^{26}$ & $\begin{array}{l}\text { - } 45.1 \% \text { of patients were nonadherent ( } \leq 75 \% \text { of doses taken) over } 6 \text { months of treatment } \\
\text { - Low level of social support rated by case manager and poor early medication acceptance were significant } \\
\text { predictors of nonadherence by logistic regression }(O R=3.5, P=0.03 \text { and } O R=\mid I . I, P<0.001) \text {, respectively } \\
\text { - The level of social support based on patient ratings was not correlated with the case managers' ratings and was } \\
\text { not significantly associated with adherence } \\
\text { - Insight into illness did not differ between adherent and nonadherent groups }\end{array}$ \\
\hline Mohamed et a ${ }^{27}$ & $\begin{array}{l}\text { - Nonadherence percentage not reported } \\
\text { - ITAQ and DAI scores were significantly positively correlated }(r=0.32, P<0.000 \mathrm{I}) \\
\text { - Attitude toward medication but not insight at baseline were significantly associated with medication adherence in } \\
\text { prospective assessments }(P<0.00 \mathrm{I} \text { and } P>0.05 \text {, respectively) } \\
\text { - In a model not including attitude toward medication, insight was significantly associated with medication } \\
\text { adherence }\end{array}$ \\
\hline
\end{tabular}


Table 2 (Continued)

\begin{tabular}{|c|c|}
\hline References & Results \\
\hline Morken et $\mathrm{al}^{28}$ & $\begin{array}{l}\text { - } 44 \% \text { of patients were nonadherent to oral antipsychotics over the study period ( I month or } 4 \text { separate week } \\
\text { without medication) } \\
\text { - Patients with relatives showing low expressed emotion at baseline were significantly less adherent over the study } \\
\text { period than those with relatives showing high expressed emotion (OR }=6.0,95 \% \mathrm{Cl} \text { : I.07-34.13, } P=0.042 \text { ) } \\
\text { - Low expressed emotion is a marker of nonsupportive families }\end{array}$ \\
\hline Liu-Seifert et a $\left.\right|^{29}$ & $\begin{array}{l}\text { - A higher level of perceived beneficial effect of medication was the only factor associated with significantly } \\
\text { reduced likelihood of early treatment discontinuation ( } \mathrm{HR}=0.56,95 \% \mathrm{Cl}: 0.40-0.79, P=0.00 \mathrm{I}) \text {; ie, a higher level of } \\
\text { perceived medication benefit by I point, such as strong vs mild or mild vs none, was associated with } 44 \% \text { less risk } \\
\text { of discontinuation from the study during the following visit }\end{array}$ \\
\hline de Haan et $\mathrm{al}^{30}$ & $\begin{array}{l}\text { - The mean medication adherence score over } 5 \text { years was } 2.6(1 \%,<25 \% ; 3 \%,>75 \%) \\
\text { - } 67.5 \% \text { had score } 2.5-3.0 \text {, indicating high adherence } \\
\text { - Multivariable analysis: hostility and uncooperativeness }(P=0.007) \text {, involuntary admission }(P=0.02) \text { but not cannabis } \\
\text { use, SWN and ROMI total scores, and insight were associated with adherence during } 5 \text {-year follow-up } \\
\text { - Therapeutic alliance during acute admission appears to be critical for long-term adherence }\end{array}$ \\
\hline McEvoy et $\mathrm{al}^{31}$ & $\begin{array}{l}\text { - Nonadherence defined as not taking any medication for }>7 \text { consecutive days (\% not reported) } \\
\text { - Better insight treated as a time-dependent covariate was associated with longer time to nonadherence }(P=0.0076) \\
\text { throughout the study } \\
\text { - Baseline insight was not significantly related to the probability of early discontinuation }\end{array}$ \\
\hline Kamali et a $\left.\right|^{32}$ & $\begin{array}{l}\text { - } 33 \% \text { of patients were nonadherent }(\leq 74 \% \text { of doses taken) over the past } 3 \text { months of treatment } \\
(O R=7.80, P=0.01) \text {, drug misuse }(O R=4.38, P=0.04) \text {, lack of insight }(O R=4.22, P=0.04) \\
\text { - Positive symptoms }(O R=7.5, P=0.01 \text { ) and lack of insight }(O R=4.98, P=0.03) \text { were the most significant predictors } \\
\text { of nonadherence in patients without substance/alcohol abuse }\end{array}$ \\
\hline Yamada et $\mathrm{al}^{33}$ & $\begin{array}{l}\text { - I6.7\% of patients were nonadherent during the follow-up } \\
\text { - The score of "fulfillment of life goals" (good insight) was greater in the adherent compared with the nonadherent } \\
\text { group ( } P=0.015) \\
\text { - The score of "no perceived daily benefit" (poor insight) was greater in the nonadherent compared with the } \\
\text { adherent group ( } P=0.018 \text { ) } \\
\text { - No significant difference in patient characteristics or scores of BPRS, GAF, or other ROMI items }\end{array}$ \\
\hline Ascher-Svanum et a ${ }^{34}$ & $\begin{array}{l}\text { - } 18.8 \% \text { of patients were nonadherent during the first year }(M P R \leq 80 \%) \\
\text { The best predictors of nonadherence were prior nonadherence }(O R=4 . I, P<0.001) \text {, illicit drug use }(O R=1.8 \text {, } \\
P=0.025) \text {, alcohol use }(O R=1.6, P=0.008) \text {, prior antidepressant use }(O R=1.4, P=0.02) \text {, cognitive impairment } \\
(O R=1.3, P<0.00 I)\end{array}$ \\
\hline
\end{tabular}

Abbreviations: BPRS, Brief Psychiatric Rating Scale; Cl, confidence interval; DAl, Drug Attitude Inventory; GAF, Global Assessment of Functioning; HR, hazard ratio; ITAQ, Insight and Treatment Attitudes Questionnaire; MEMS, Medication Event Monitoring System; MPR, Medication Possession Ratio; OR, odds ratio; ROMI, Rating of Medication Influences; SMI, serious mental illness; SWN, Subjective Well-Being Under Neuroleptics.

\section{Reasons for intentional nonadherence}

Intentional nonadherence refers to a conscious patient decision to stop taking medication or to take less medication than is prescribed. The identified reasons in this category include poor insight, a negative attitude toward medication, distressing medication side effects, poor therapeutic alliance, and stigma.

\section{Insight}

A total of 20 studies analyzed the relationship between insight and adherence; of which 11 were prospective (Tables 1 and 2) and 9 were cross-sectional (Tables 3 and 4). Instruments used in most of the studies measured at least 2 domains of insight: awareness of illness, and awareness of need for treatment. Results were expressed as a combined insight score or separately for each domain.

\section{Prospective studies}

In patients with schizophrenia, including a first-episode illness, poor insight was a significant predictor of nonadherence ${ }^{21,32}$ and was associated with a shorter time to medication discontinuation. ${ }^{31}$ Another study in patients with schizophrenia reported that baseline scoring on a standardized insight scale ${ }^{56}$ differed significantly between adherent and nonadherent patients. ${ }^{33}$ Better insight reflected by scores in 3 insight domains was associated with improved adherence in patients with schizophrenia or bipolar disorder. ${ }^{19}$ In bipolar disorder, poor insight after acute mania treatment was associated with a greater probability of nonadherence during maintenance therapy. ${ }^{23}$ Two reports that did not show a significant association between insight and adherence were studies in first-episode psychosis that assessed insight from 


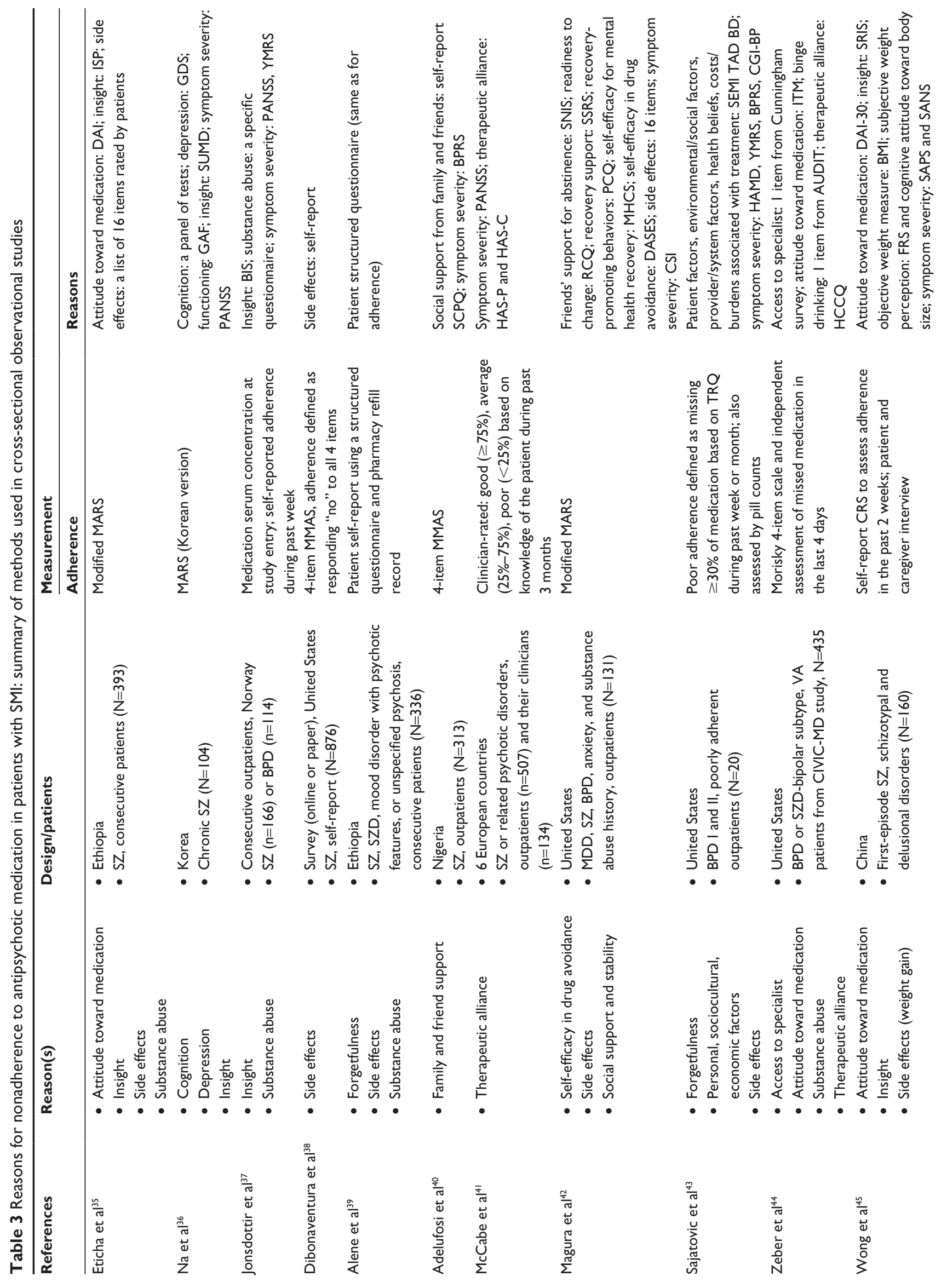



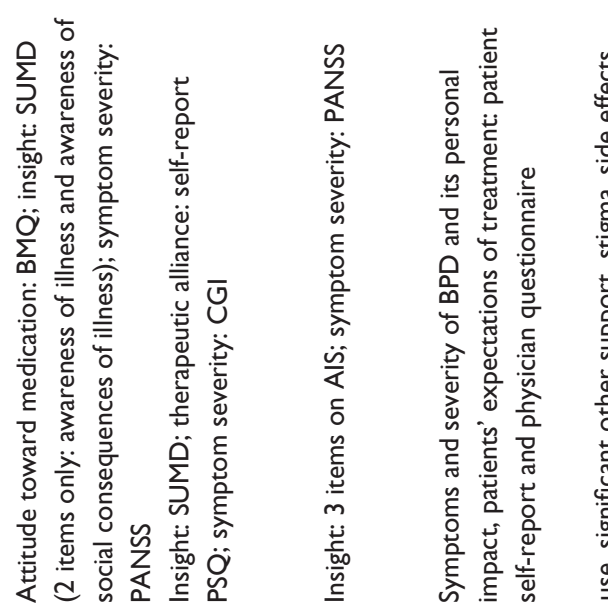

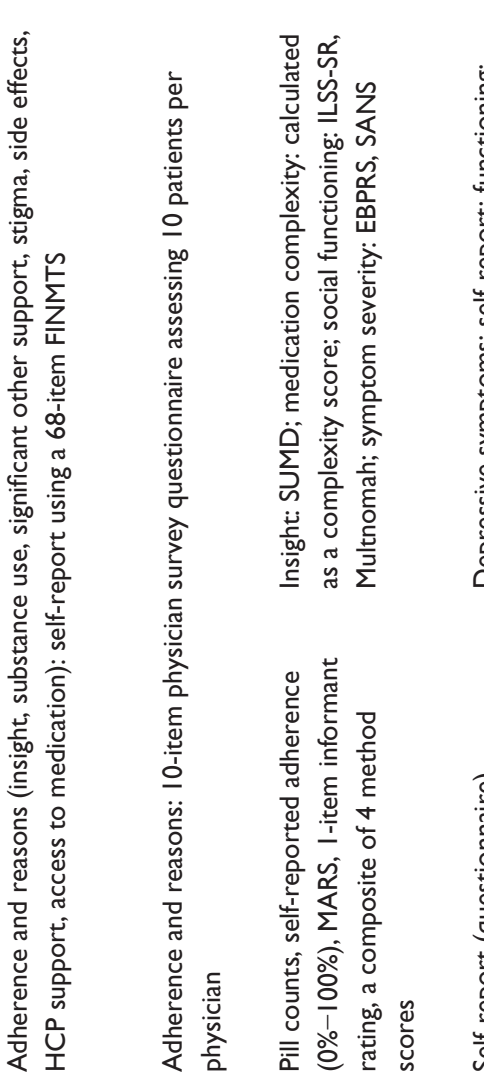

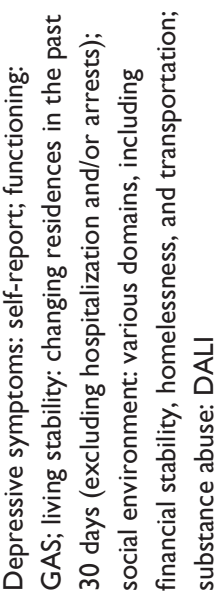

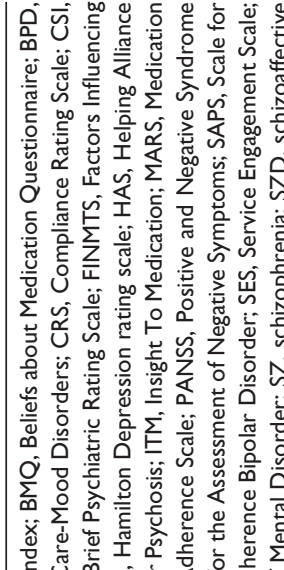

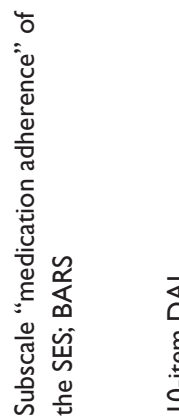

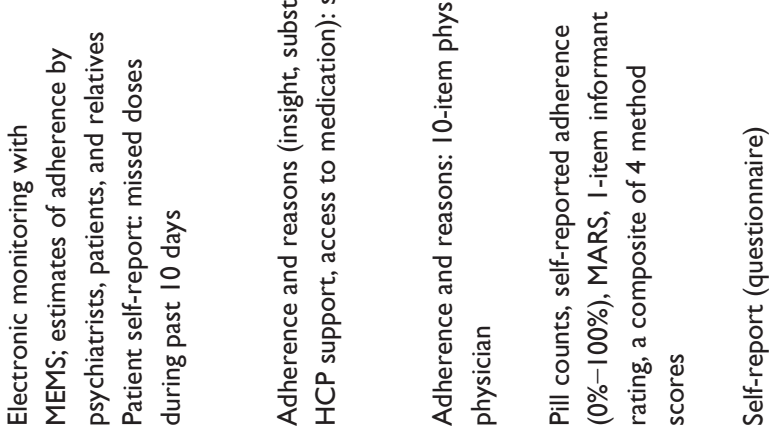

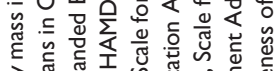

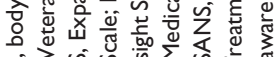

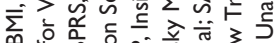

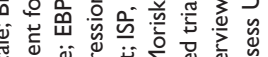

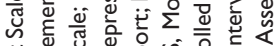

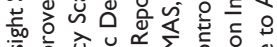

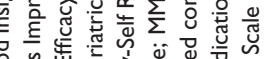

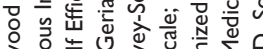

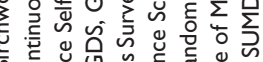

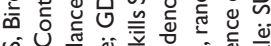

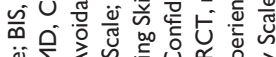

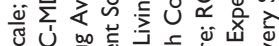

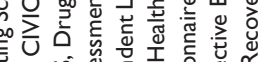
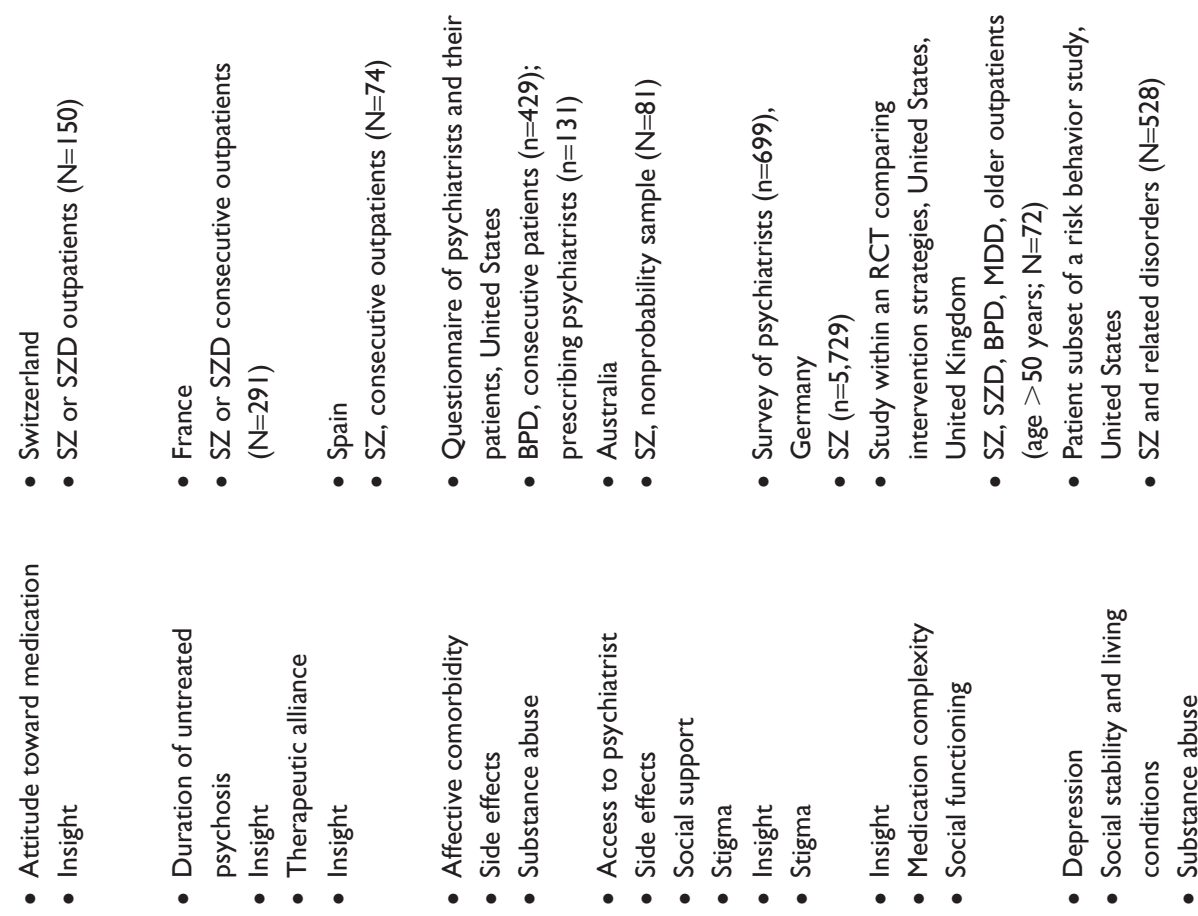

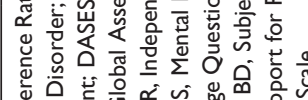

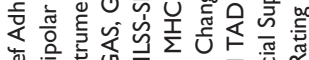

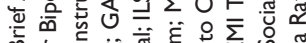

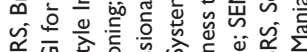

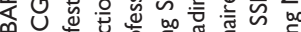

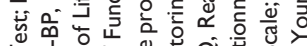

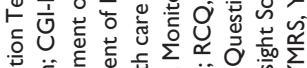

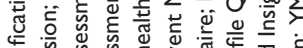

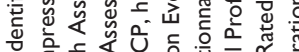

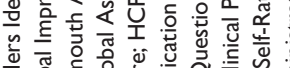

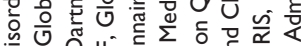

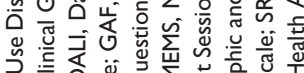

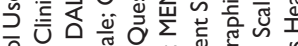

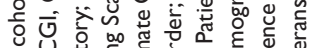

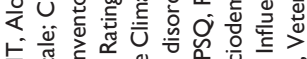

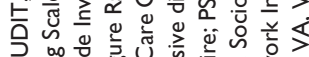

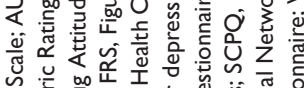

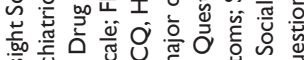

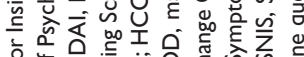

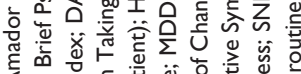

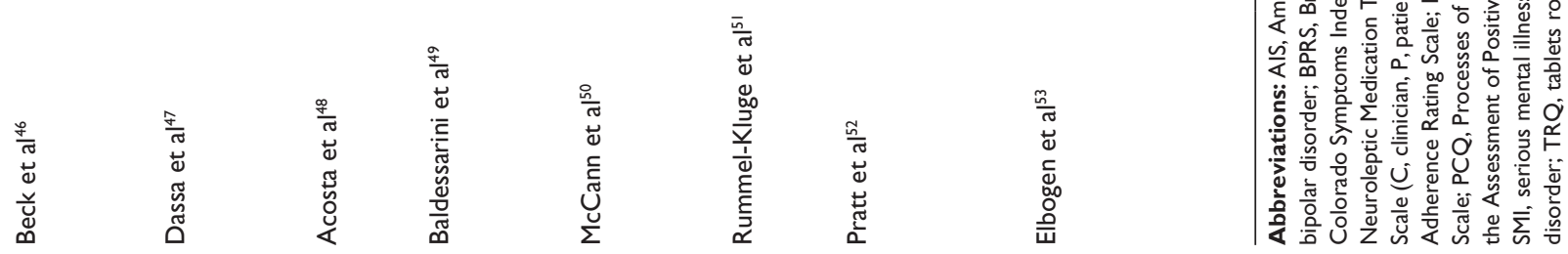


Table 4 Reasons for nonadherence to antipsychotic medication in patients with SMI: results of cross-sectional observational studies

\begin{tabular}{|c|c|}
\hline References & Results \\
\hline Eticha et $\mathrm{al}^{35}$ & $\begin{array}{l}\text { - Nonadherence rate was } 26.5 \% \\
\text { - Better adherence was significantly associated with positive attitude toward medication }(\mathrm{OR}=\mathrm{I} .40,95 \% \mathrm{Cl} \text { : } \\
\text { I.26-I.55); fewer medication side effects (OR =0.97, } 95 \% \mathrm{Cl}: 0.94-0.99) \text {; less khat chewing }(\mathrm{OR}=0.24,95 \% \mathrm{Cl} \text { : } \\
0.09-0.68) \text {; and } 2 \text { dimensions of insight: better ability to relabel symptoms (OR =I.57, } 95 \% \mathrm{Cl}: \mathrm{I} .19-2.07) \text { and } \\
\text { better awareness of illness (OR =I.44, } 95 \% \mathrm{Cl} \text { : I.I2-I.85) }\end{array}$ \\
\hline $\mathrm{Na}$ et $\mathrm{al}^{36}$ & $\begin{array}{l}\text { - Nonadherence rate was } 15.4 \% \\
(P=0.03) \text {, and I of the cognitive measures: number of errors in word reading }(P=0.0008)\end{array}$ \\
\hline Jonsdottir et $\mathrm{al}^{37}$ & $\begin{array}{l}\text { - Adherence in SZ: } 33.8 \% \text { partial adherence, } 1 \text { I\% nonadherence } \\
\text { - Adherence in BPD: } 26.2 \% \text { partial adherence, } 16.5 \% \text { nonadherence } \\
\text { - Patients with SZ from a full-adherence group showed a significantly higher mean level of insight compared with } \\
\text { those from a nonadherent group } \\
\text { - The difference was not significant for patients with BPD } \\
\text { - The use of illicit substances and alcohol was greater in nonadherent and partially adherent groups in both SZ and } \\
\text { BPD compared with that in the adherent groups }\end{array}$ \\
\hline Dibonaventura et $\mathrm{al}^{38}$ & $\begin{array}{l}\text { - } 57.5 \% \text { of patients were nonadherent } \\
\text { - } 71.7 \% \text { of patients were taking atypical antipsychotics } \\
\text { - } 80 \% \text { of respondents reported } \geq I \text { medication side effect } \\
\text { - Agitation/EPS (OR }=0.57, P=0.0007) \text {, sedation/cognition ( } O R=0.70, P=0.033) \text {, prolactin/endocrine effects } \\
(O R=0.69, P=0.034) \text {, metabolic effects, including weight gain }(O R=0.64, P=0.008) \text { were associated with } \\
\text { nonadherence }\end{array}$ \\
\hline Alene et $\mathrm{al}^{39}$ & $\begin{array}{l}\text { - } 52.1 \% \text { of patients were fully adherent (self-report) but only } 19.6 \% \text { based on refill data } \\
\text { - Forgetfulness was stated as the main reason for missing medication ( } 36.2 \%) \\
\text { - Experiencing side effects, exposure to social drugs, and number of medications taken concurrently were } \\
\text { associated with worse adherence }\end{array}$ \\
\hline Adelufosi et $\mathrm{al}^{40}$ & $\begin{array}{l}\text { - } 40.3 \% \text { of patients were nonadherent } \\
\text { adherence was significantly better among respondents with good level of perceived social support from families } \\
\text { (univariate analysis) } \\
\text { - Poor outpatient clinic attendance }(O R=4.97, P=0.001) \text {, moderate satisfaction with outpatient care }(O R=2.78 \text {, } \\
P=0.002) \text {, and symptom severity }(O R=1.08, P=0.001) \text { were independent predictors of nonadherence } \\
\text { (multivariable analysis) }\end{array}$ \\
\hline McCabe et $\mathrm{al}^{41}$ & $\begin{array}{l}\text { - } 24.3 \% \text { of patients had average or poor adherence } \\
\text { - Patient and clinician ratings of therapeutic alliance weakly correlated }\left(r_{s}=0.13, P=0.004 \text {; ie, the perspectives }\right. \\
\text { differ) } \\
\text { - For each unit increase in clinician-rated therapeutic alliance score, the OR of good adherence was increased by } \\
65.9 \%(95 \% \mathrm{Cl}: 34.6 \%-104.5 \%) \\
\text { - For each unit increase in patient-rated therapeutic alliance score, the OR of good adherence was increased by } \\
20.8 \%(95 \% \mathrm{Cl}: 4.4 \%-39.8 \%)\end{array}$ \\
\hline Magura et $\mathrm{al}^{42}$ & $\begin{array}{l}\text { - } 71 \% \text { of patients were at least partially nonadherent } \\
\text { - } 3 \text { factors were significantly associated with adherence: self-efficacy for drug avoidance, medication side effects, } \\
\text { and recovery support (multivariable analysis) } \\
\text { - The final model explained } 21 \% \text { of the variance in adherence, indicating that other factors were not } \\
\text { accounted for } \\
\text { - Intensity of substance use was not associated with adherence }\end{array}$ \\
\hline Sajatovic et $\mathrm{al}^{43}$ & $\begin{array}{l}\text { - } 41 \%-43 \% \text { of patients were nonadherent } \\
\text { - Forgetting to take medication and side effects were the most common self-reported reasons for nonadherence } \\
\text { ( } 55 \% \text { and } 20 \% \text {, respectively) } \\
\text { - Difficulty with medication routine, denial of illness severity, and fear of medication side effects ranked highest } \\
\text { among negative attitudes toward medication } \\
\text { - } 95 \% \text { of participants reported good relationship with their HCP } \\
\text { - The results may reflect adherence problems independent of therapeutic alliance }\end{array}$ \\
\hline Zeber et $\mathrm{al}^{44}$ & $\begin{array}{l}\text { - } 46 \% \text { of patients had adherence problems } \\
\text { - Multivariable analysis: OR of reasons most influencing poor adherence ( } 95 \% \mathrm{Cl}) \text { : attitude toward medication, } 2.4 \mathrm{I} \\
\text { (I.I7-3.9I); binge drinking, I.95 (I.04-2.93); limited access to mental health specialist, I.73 (I.08-2.69) } \\
\text { - Therapeutic alliance did not show statistical significance in the same model }(\mathrm{OR}=\mathrm{I} .55,95 \% \mathrm{Cl}: 0.94-2.13, \mathrm{P}=0.09)\end{array}$ \\
\hline
\end{tabular}


Table 4 (Continued)

\begin{tabular}{|c|c|}
\hline References & Results \\
\hline Wong et a ${ }^{45}$ & $\begin{array}{l}\text { - Multivariable analysis: perception of being overweight was associated with significantly worse adherence } \\
(P<0.0 \text { I }) \text {; better attitude toward medication }(P<0.0 \mathrm{I}) \text { and insight into illness }(P=0.006) \text { were associated with } \\
\text { significantly better adherence } \\
\text { - Attitude toward medication was the most influential factor } \\
\text { - } 72 \% \text { of patients who believed that antipsychotics led to weight gain had reduced/omitted the drug dosages }(P<0.00 \mathrm{I}) \\
\text { - The concerns of weight gain occurred in those who perceived themselves as overweight and contributed } \\
\text { significantly to poor adherence }\end{array}$ \\
\hline Beck et $\mathrm{al}^{46}$ & $\begin{array}{l}\text { - Attitude toward antipsychotic medication impacts adherence over and above insight into illness; it differs from } \\
\text { attitude toward medication in general in association with adherence } \\
\text { - Attitude toward antipsychotic medication has } 2 \text { dimensions interacting with each other: necessity and concerns } \\
\text { - Awareness of illness influences adherence indirectly through perceived necessity of medication }\end{array}$ \\
\hline Dassa et a $\mathrm{a}^{47}$ & $\begin{array}{l}\text { - } 30 \% \text { of patients were nonadherent } \\
95 \% \mathrm{Cl}: 1.05-9.89) \text {, a lower level of therapeutic alliance (OR }=0.45,95 \% \mathrm{Cl}: 0.32-0.64) \text {, and duration of } \\
\text { untreated psychosis (OR }=1.12,95 \% \mathrm{Cl} \text { : I.03-I.22) } \\
\text { - Awareness of effect of medication was more important than awareness of illness for adherence }\end{array}$ \\
\hline Acosta et $\mathrm{al}^{48}$ & $\begin{array}{l}\text { - } 24.3 \% \text { of patients were nonadherent ( } \leq 75 \% \text { MEMS adherence) } \\
\text { - Subjective assessments of adherence were in agreement with the MEMS in } 77 \%-78 \% \text { of cases when rated by } \\
\text { psychiatrists, patients, and relatives } \\
\text { - Multivariable analysis: nonadherence was associated with poor insight }(O R=1.22, P=0.04) \text { and higher scores on } \\
\text { the PANSS items indicating conceptual disorganization (OR }=1.74, P=0.07)\end{array}$ \\
\hline Baldessarini et a ${ }^{49}$ & $\begin{array}{l}\text { - } 33.8 \% \text { of patients were nonadherent }(\geq I \text { missed dose in last } 10 \text { days, patient self-report) } \\
\text { - Multivariable analysis: factors significantly }(P<0.05) \text { and independently associated with nonadherence: alcohol } \\
\text { dependence }(O R=4.89)>\text { cognitive side effects }(O R=2.59)>\text { affective comorbidity }(O R=I .10) \\
\text { - Major adverse effects associated with nonadherence in patients with self-reported nonadherence: weight gain } \\
(58.5 \%) \text {, excessive sedation }(54.2 \%) \text {, physical awkwardness or tremor }(33.1 \%)\end{array}$ \\
\hline McCann et $\mathrm{al}^{50}$ & $\begin{array}{l}\text { - } 19.7 \% \text { of patients were nonadherent ( } \geq \mathrm{I} \text { missed dose over the past week) } \\
\text { - Multivariable analysis: independent predictors of nonadherence were self-rated poor access to psychiatrists } \\
\text { - Stigma was not associated with nonadherence }\end{array}$ \\
\hline Rummel-Kluge et $\mathrm{a}^{51}$ & $\begin{array}{l}\text { - } 68 \%-69 \% \text { of patients were considered partially nonadherent (for unintentional partial nonadherence: missing } \\
\text { I dose in last month) } \\
\text { - The most common reasons for partial adherence were lack of insight into the need for prophylactic medication } \\
\text { (68\%), lack of insight/denial of illness }(63 \%-66 \%) \text {, and stigma (embarrassment about taking daily medication, } 62 \% \text { ) }\end{array}$ \\
\hline Pratt et a ${ }^{52}$ & $\begin{array}{l}\text { - Mean nonadherence rate was } ~ 40 \% \text { based on pill count, but only } 9 \%-17 \% \text { based on self-report and MARS score } \\
\text { relative to BPD or MDD, higher level of medication supervision, greater level of insight, more prescribed } \\
\text { medications, fewer negative symptoms, and better community functioning }\end{array}$ \\
\hline Elbogen et $\mathrm{al}^{53}$ & $\begin{array}{l}\text { - } 22 \% \text { of patients were nonadherent (doses taken never or sometimes during past } 30 \text { days) } \\
P=0.0177 \text { ), functional impairment }(O R=1.94 ; P=0.0023) \text {, having moved in the past } 30 \text { days }(O R=1.92 ; P=0.0028) \text {, } \\
\text { feeling emotionally numb ( } O R=2.18 ; P=0.0006) \text {, loss of interest in daily activities ( } O R=1.81 ; P=0.0075) \text {, and } \\
\text { reporting recent suicidal ideation ( } O R=1.98 ; P=0.0047) \\
\text { - Substance abuse, living instability, and depressive symptoms increased the probability of nonadherence from } 0.14 \\
\text { to } 0.66 \\
\text { - The relationship between substance abuse and adherence was not mediated by depression or living instability - } \\
\text { the effect is independent for all } 3 \text { factors }\end{array}$ \\
\hline
\end{tabular}

Abbreviations: BPD, bipolar disorder; Cl, confidence interval; EPS, extrapyramidal symptoms; HCP, health care professional; MARS, Medication Adherence Rating Scale; MDD, major depressive disorder; MEMS, Medication Event Monitoring System; OR, odds ratio; PANSS, Positive and Negative Syndrome Scale; SZ, schizophrenia.

a single item on the Positive and Negative Syndrome Scale (PANSS). ${ }^{26,30}$

\section{Cross-sectional studies}

Poor insight was significantly associated with nonadherence in patients with schizophrenia, ${ }^{48}$ with first-episode schizophrenia and related disorders, ${ }^{45}$ and in patients aged $>50$ years with schizophrenia, bipolar disorder, or MDD. ${ }^{52}$ Mean scores on an insight scale ${ }^{57}$ were significantly greater (indicating improved insight) in patients with schizophrenia who were fully adherent compared with those who were nonadherent, but the association was on a trend level and not statistically 


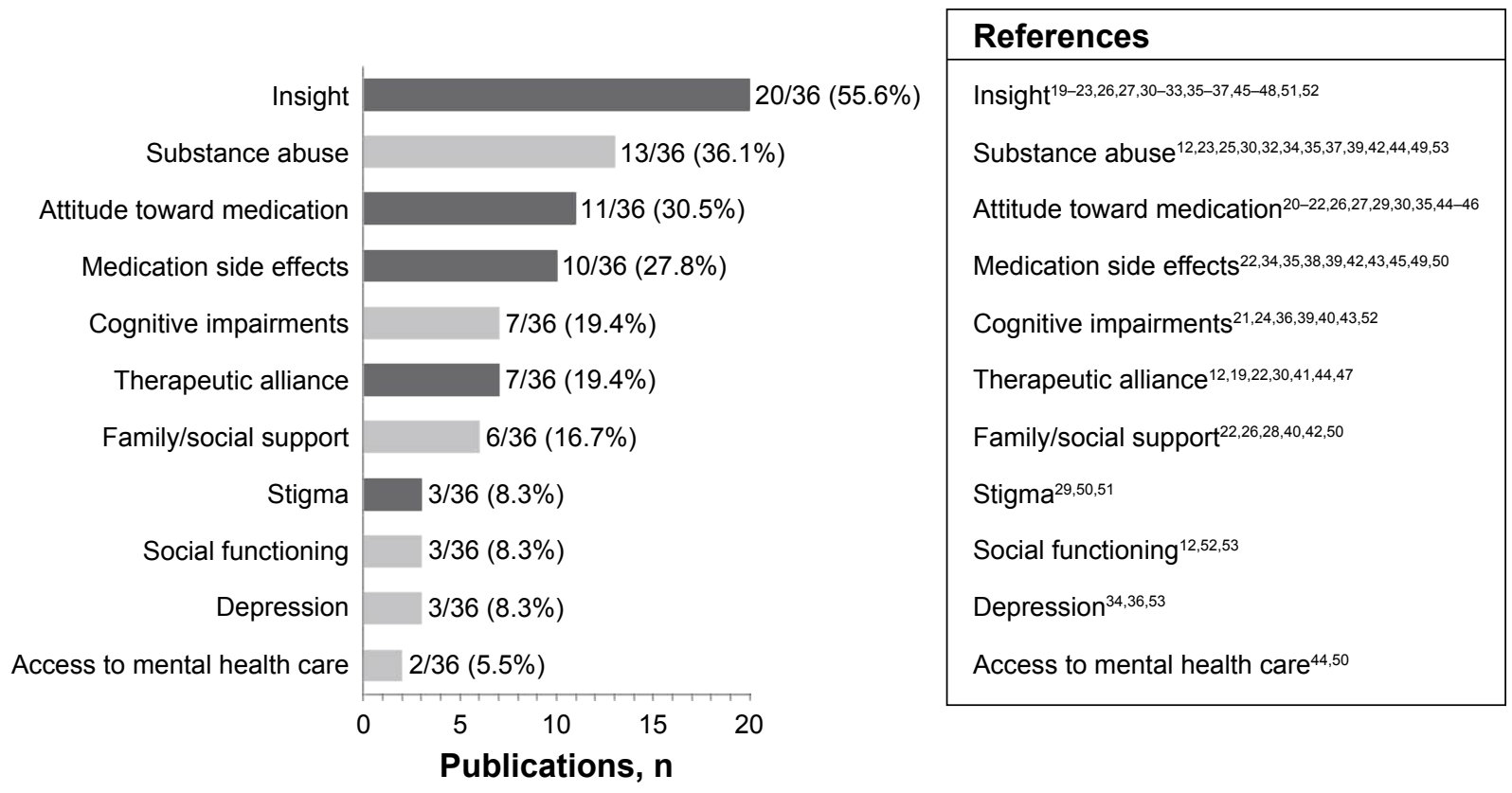

Reason for intentional nonadherence

Reason for unintentional nonadherence

Figure 2 Number of studies investigating specific reasons for nonadherence.

significant in patients with bipolar disorder. ${ }^{37}$ When a specific domain of insight was assessed, awareness of need for treatment but not awareness of illness was significantly associated with adherence in patients with schizophrenia and schizoaffective disorder. ${ }^{47}$ Similarly, poor awareness of need for treatment was associated with poor adherence in Korean patients with chronic schizophrenia. ${ }^{36}$ In contrast, a study from Ethiopia found that awareness of illness and ability to positively reassess experiences/symptoms, but not awareness of need for treatment, were associated with better adherence in patients with schizophrenia. ${ }^{35}$ In a survey of European clinicians, lack of insight into the need for prophylactic medication and lack of insight into illness were the most frequently cited reasons for partial adherence in schizophrenia. ${ }^{51}$

\section{Attitude toward medication}

Eleven studies analyzed the relationship between medication adherence and attitude toward medication. All demonstrated a significant positive association wherein negative attitudes were associated with poor adherence. Seven studies were prospective (Tables 1 and 2) and 4 were cross-sectional (Tables 3 and 4). The instrument used most frequently to assess attitude toward medication was the Drug Attitude Inventory (DAI, 54.5\%, 6/11)..$^{58}$

\section{Prospective studies}

In 2 studies of patients with first-episode schizophrenia-spectrum psychoses, poor early medication acceptance at study entry ${ }^{26}$ and hostility and uncooperativeness at first admission ${ }^{30}$ were the most significant predictors of nonadherence. ${ }^{26,30}$ These results support the common clinical impression that the patient's early attitude toward medication impacts adherence and persists throughout the treatment. It is of note that prior nonadherence was the best predictor of nonadherence in 2 large studies of patients with schizophrenia. ${ }^{12,34}$ However, this phenomenon indicates predictability of future behavior based on past behavior and may be driven by other reasons (eg, those associated with unintentional nonadherence) in addition to attitude toward medication.

A positive attitude toward medication at baseline in combination with good psychosocial function was the best predictor of objectively measured mean adherence over a 12-month period in patients with schizophrenia or schizophrenia-like psychosis. ${ }^{20}$ A post hoc analysis of data from a large clinical trial in schizophrenia and schizoaffective disorder reported that perceived medication benefit was the only significant predictor of early treatment discontinuation. ${ }^{29}$ An analysis of data from another large clinical trial of patients with schizophrenia (CATIE) found that a positive attitude toward medication at baseline was associated with better adherence, and a change toward a more 
positive attitude improved adherence during the study. ${ }^{27} \mathrm{Of}$ note, a best-fitting model to explain nonadherence included attitude toward medication but not insight into need for the treatment and awareness of illness. ${ }^{27}$ In contrast, results from a study of Chinese patients with schizophrenia showed that attitude toward medication was not required in a model that predicted nonadherence and included measures of insight and symptom severity; however, patients who were nonadherent had significantly worse attitudes toward medication compared with those who were adherent at follow-up. ${ }^{21}$ A more detailed analysis identified attitude toward medication as a mediator of 2 domains of insight: awareness of consequences of illness and awareness of the need for medication. ${ }^{22}$ In that study, adherence of patients with earlyepisode schizophrenia or schizoaffective disorder 6 months after hospital discharge was directly predicted by attitude toward medication, symptom severity, and early stage of the illness but not by insight.

\section{Cross-sectional studies}

An Ethiopian study found that negative attitude toward medication was significantly associated with nonadherence in patients with schizophrenia. ${ }^{35}$ A Chinese study in first-episode schizophrenia found a similar association, ${ }^{45}$ as did a study in US veterans with bipolar disorder. ${ }^{44}$ A study of patients with schizophrenia and schizoaffective disorder showed that attitude toward antipsychotic medication comprised dimensions of "necessity" and "concerns" that impact adherence directly and independently of each other. These 2 dimensions differ from attitude toward pharmacotherapy in general, which was not found to be a direct predictor of adherence. ${ }^{46}$

\section{Relationship between insight and attitude toward medication} A longitudinal analysis of adherence from a large prospective study of patients with schizophrenia showed that baseline insight measured as awareness of illness and awareness of need for treatment was significantly associated with adherence only in a model that did not include a measure of attitude toward medication. ${ }^{27}$ Similarly, in patients with schizophrenia or schizophrenia-like psychosis, poor awareness of illness was a significant predictor of nonadherence in a univariate analysis but was not required for the best model fit in a multivariable model that included a measure of attitude toward medication..$^{20}$ Better awareness of illness and awareness of need for treatment were associated with better adherence in early schizophrenia, although the 2 domains of insight were predictors of attitude toward medication, which in turn was a direct predictor of adherence. ${ }^{22}$ Similar results were obtained from a cross-sectional study of patients with schizophrenia and schizoaffective disorder using a structural equation model ${ }^{46}$ In that model, the relationship between insight (awareness of illness and social consequences of illness) and adherence was mediated by attitude toward medication, specifically by the dimension of perceived necessity for treatment. ${ }^{46}$

\section{Medication side effects}

Ten studies analyzed the relationship between medication side effects and adherence: 2 were prospective and 8 were cross-sectional. In a large prospective study of patients with schizophrenia, patient-reported cognitive impairment resulting from antipsychotic medication was included among the 5 strongest predictors of nonadherence. ${ }^{34}$ Conversely, patients with early schizophrenia who were adherent 6 months after discharge from the hospital experienced significantly more severe side effects compared with patients who were nonadherent. ${ }^{22}$

Results from a US nationwide cross-sectional survey of patients with schizophrenia identified 4 categories of side effects that were each associated with significantly less adherent behavior. ${ }^{38}$ Experiencing greater side effects was significantly associated with worse adherence in Ethiopian patients with schizophrenia. ${ }^{35,39}$ In another study of patients with schizophrenia, having side effects was among 3 independent variables included in a model that predicted nonadherence of patients in Australia. ${ }^{50}$ Having side effects was also among 3 independent variables in a model predicting nonadherence of patients with SMI who had a recent history of substance abuse or addiction ${ }^{42}$ and the second most common reason for nonadherence identified in poorly adherent patients with bipolar disorder. ${ }^{43}$ Results from a nationwide US survey of physicians and their patients with bipolar disorder showed that having side effects was among 6 categories of independent variables significantly associated with nonadherence; weight gain was a side effect most frequently linked to nonadherence by patients who identified themselves as nonadherent. ${ }^{49}$ Interestingly, a perceived but not actual overweight status was associated with poor adherence and was among the 3 most influential factors contributing to nonadherence of Chinese patients with first-episode schizophrenia and related disorders. ${ }^{45}$

\section{Therapeutic alliance}

Therapeutic alliance is a broad concept denoting the quality of relationship between patient and clinician. Seven studies, 
4 prospective and 3 cross-sectional, analyzed the association between therapeutic alliance and adherence. Physicianreported therapeutic alliance was strongly correlated with adherence at baseline, and improved therapeutic alliance was correlated with improved adherence after 1 year of follow-up based on a post hoc analysis of data from a prospective, observational study of patients with schizophrenia or bipolar disorder. ${ }^{19}$ In another prospective observational study, better patient-reported therapeutic alliance at baseline was associated with better adherence of patients with early-episode schizophrenia 6 months after hospital discharge. ${ }^{22}$ However, the variable was not required in a best-fitting model predicting adherence that included attitude toward medication, symptom severity, and stage of illness. ${ }^{22}$ For patients with first-episode schizophrenia and related disorders, the only significant predictor of nonadherence during a 5-year follow-up study was negative therapeutic alliance, which was assessed based on the level of hostility and uncooperativeness at admission and involuntary admission. ${ }^{30}$ Hostility was also among significant baseline predictors of nonadherence over 3 years based on a post hoc analysis of data from a prospective observational study of patients with schizophrenia. ${ }^{12}$

Results from a cross-sectional study conducted to examine the relationship between therapeutic alliance and adherence of patients with schizophrenia or related disorders reported that patient- and physician-reported measures of therapeutic alliance, although only weakly correlated, were both independently and significantly associated with adherence. However, no other variables were assessed in that study except for symptom severity. ${ }^{41}$ Low level of patientreported therapeutic alliance was a significant predictor of poor attitude toward medication, which was used as a proxy for nonadherence in a cross-sectional study of patients with schizophrenia or schizoaffective disorder. ${ }^{47}$ In contrast, poor therapeutic alliance was not a significant predictor of nonadherence in a model that included negative medication beliefs, binge drinking, and limited access to a mental health specialist in a cross-sectional study of US veterans with bipolar disorder. ${ }^{44}$

\section{Stigma}

Stigma refers to a feeling of disgrace because of mental illness and/or need for treatment. ${ }^{59}$ Three studies assessed stigma in relation to adherence. In a cross-sectional, 10question survey of physicians, stigma was among the 3 reasons most frequently considered as contributing to poor adherence of patients with schizophrenia. ${ }^{51}$ Stigma was not among 3 variables that predicted nonadherence in a cross-sectional study of patients with schizophrenia in Australia, although $\sim 70 \%$ of the patients indicated a feeling of stigma. ${ }^{50}$ A post hoc analysis from a large clinical trial of patients with schizophrenia and schizoaffective disorder did not identify stigma as a variable significantly predicting early treatment discontinuation. ${ }^{29}$

\section{Reasons for unintentional nonadherence}

Unintentional nonadherence occurs when practical problems or impairments related to having SMI interfere with taking medication. Unintentional nonadherence affects a patient's ability to take medication on a regular basis. Using this definition, the following reasons for nonadherence were included in this category: substance abuse, cognitive impairments, depression, family/social support, access to mental health care, and social functioning. Substance abuse was included in this category because a patient's nonadherence to medication is unintentional during the period of substance use.

\section{Substance use or abuse}

Thirteen studies analyzed the relationship between substance abuse and adherence: 6 were prospective, 7 were crosssectional, and all demonstrated a significant association.

\section{Prospective studies}

In first-episode schizophrenia or related disorders, misuse of alcohol at baseline and recent drug abuse were significant predictors of nonadherence within 6 months from the patients' first episode. ${ }^{32}$ Results from other studies in firstepisode schizophrenia or related disorders showed that baseline use of cannabis significantly increased the hazard of nonadherence and hazard of treatment discontinuation ${ }^{25}$ and was significantly correlated with nonadherence during a 5 -year period. ${ }^{30}$ However, cannabis use was not a predictor of nonadherence when hostility, uncooperativeness, and involuntary admission were entered into the model. ${ }^{30}$

Aside from past history of nonadherence, recent use of illicit drugs and recent use of alcohol were the strongest independent predictors of nonadherence in a large study of patients with schizophrenia. ${ }^{34}$ Current substance abuse and current alcohol dependence were also baseline predictors of nonadherence during follow-up in another large study of patients with schizophrenia. ${ }^{12}$ Use of cannabis during the acute phase was the most influential significant variable associated with nonadherence during the maintenance phase in patients with bipolar disorder; use of alcohol and substances other than cannabis during the study was significantly greater in the nonadherent group compared with the adherent group. ${ }^{23}$ 


\section{Cross-sectional studies}

Substance abuse was among the 3 most influential variables predicting nonadherence in patients with schizophrenia and related disorders and was independent of depressive symptoms and living instability. ${ }^{53}$ Chewing the traditional herbal stimulant khat and use of social drugs were significantly associated with poor adherence in Ethiopian patients with schizophrenia and related disorders. ${ }^{35,39}$ In schizophrenia or bipolar disorder, use of alcohol and illicit substances including cannabis was significantly greater in partially adherent or nonadherent European patients relative to those who were adherent. ${ }^{37}$ In US veterans with bipolar disorder, binge drinking was the third most influential variable significantly associated with poor adherence. ${ }^{44}$ Similarly, alcohol dependence of patients with bipolar disorder reported by physicians in a survey was the most influential variable significantly associated with nonadherence. ${ }^{49}$ In patients with SMI who had a recent history of substance abuse or addiction, lower self-efficacy for drug avoidance was among the 3 reasons included in a regression model predicting nonadherence. ${ }^{42}$

\section{Cognitive impairments}

Seven studies analyzed the relationship between variables related to impaired cognition and adherence: 2 were prospective and 5 were cross-sectional.

Patients with schizophrenia who were nonadherent at 3 months exhibited significantly worse time- and eventbased prospective memory at baseline relative to those who were adherent. ${ }^{21}$ However, prospective memory was not a significant independent predictor of adherence in a regression model but rather a moderator of the effect of insight and psychopathology. ${ }^{21}$ In patients with previously untreated first-episode schizophrenia, no relationship was found between global and domain-specific cognitive performance and adherence 6 months following admission into a specialized clinical program. ${ }^{24}$

Results from a cross-sectional study of Korean patients with chronic schizophrenia reported that poor executive function was a significant predictor of nonadherence; however, other cognitive functions, such as long-term memory, perception, and attention with working memory, were not significant. ${ }^{36}$ Forgetfulness was the most common reason for nonadherence self-reported by poorly adherent patients with schizophrenia and related disorders in Ethiopia ${ }^{39}$ and by patients with bipolar disorder. ${ }^{43}$ These results are supported by a finding from Nigeria that adherent patients took significantly smaller numbers of prescribed medications, possibly suggesting a lower burden on memory, compared with those who were nonadherent. ${ }^{40}$ In contrast, in patients aged $>50$ years with schizophrenia, bipolar disorder, or MDD, a greater number of received medications and greater medication treatment complexity were correlated with better informant-rated adherence, although not with self-reported adherence or adherence estimated by pill counts. ${ }^{52}$

\section{Family/social support}

Six studies assessed family and/or social support as potential reasons affecting adherence: 3 were prospective and 3 were cross-sectional. Among patients with early-episode schizophrenia, greater perceived family involvement in treatment and more positive family attitude toward medication at discharge from the hospital were significantly associated with adherence 6 months after discharge but were not included in a best-fitting regression model predicting adherence at 6 months. ${ }^{22}$ Results from a randomized clinical trial comparing long-term outcomes from integrated and standard treatment interventions of patients with recent-onset schizophrenia or related disorders reported that living in families with low expressed emotions (suggesting poor attitude and feelings expressed by a relative about a mentally ill family member) at baseline was a significant long-term predictor of poor adherence. ${ }^{28}$ In another prospective study, a low level of social support as rated by case managers, but not by patients, was found to be a major predictor of nonadherence in patients with first-episode psychosis. ${ }^{26}$

Patients with schizophrenia in Nigeria who reported good social support had better adherence compared with those reporting poor social support, but the level of support was not an independent variable included in a best-fitting regression model predicting nonadherence. ${ }^{40}$ In patients with SMI who had a recent history of substance abuse or addiction, lower social support for mental health recovery was among 3 reasons predicting nonadherence in a regression model. ${ }^{42}$ However, family involvement assessed as support from significant others in a study of patients with schizophrenia in poor regions of Australia was not an independent variable in a best-fitting regression model predicting nonadherence..$^{50}$ In that study, poor access to a psychiatrist and experiencing side effects were identified as the most significant predictors of nonadherence. ${ }^{50}$

\section{Access to mental health care}

Two cross-sectional studies assessed the association between access to a psychiatrist and adherence. In a study of US veterans with bipolar disorder receiving treatment at a large 
mental health facility in western Pennsylvania, limited access to a mental health specialist was among 3 independent variables most influencing poor adherence in a regression model that also included low medication beliefs (a negative attitude toward medication) and binge drinking. ${ }^{44}$ A crosssectional study of patients with schizophrenia residing in economically disadvantaged and poorly accessible regions in Australia found that difficulty accessing a psychiatrist was the most influential predictor of nonadherence in a regression model. ${ }^{50}$

\section{Social functioning}

Three studies assessed the association between variables related to social functioning and adherence. A post hoc analysis of data from a prospective observational study of patients with schizophrenia reported that being socially inactive and having independent housing at baseline were predictors of nonadherence during 3 years of follow-up. ${ }^{12}$ Social instability, specifically having moved in the past 30 days, was among the 3 most influential variables predicting nonadherence in patients with schizophrenia and related disorders and was independent of depressive symptoms and substance abuse. ${ }^{53}$ Good community functioning correlated with informant-rated adherence but not with pill counts or self-reported adherence of patients aged $>50$ years with schizophrenia, bipolar disorder, or MDD. ${ }^{52}$

\section{Depression}

Three studies analyzed the relationship between depression and adherence in patients with schizophrenia or related disorders. Use of antidepressants before enrollment was among the 5 best predictors of nonadherence in a regression model that analyzed data from a large prospective study. ${ }^{34}$ Having depressive symptoms, specifically feeling emotionally numb, was among 3 variables predicting nonadherence independent of social instability and substance abuse. ${ }^{53}$ Having more severe depressive symptoms was among the 3 most significant variables associated with nonadherence of patients with chronic schizophrenia in Korea. ${ }^{36}$

\section{Discussion}

This systematic review of modifiable reasons why patients with SMI do not take their prescribed antipsychotic medication found 11 patient-, HCP-, or family-reported factors that seem to drive adherence behavior. The reasons are often interrelated and have been linked to intentional or unintentional nonadherence. This review has focused on modifiable reasons because these can potentially be addressed with targeted interventions.
Regardless of diagnosis and stage of illness, variables that showed a significant association with intentional nonadherence in most studies were insight, attitude toward medication, and therapeutic alliance. Measures of several dimensions of insight were shown to correlate with measures of attitude toward medication ${ }^{46}$ or therapeutic alliance, ${ }^{19}$ additionally, both insight and therapeutic alliance seem to predict the attitude toward medication, ${ }^{60}$ which indicates that these 3 variables are closely related. More detailed analyses that examined the relationship among these variables suggested that the effect of insight and therapeutic alliance on adherence is indirect and likely mediated by attitude toward medication. 22,27,46 Therefore, attitude toward medication seems to be a key reason for intentional nonadherence and a mediator of effects of other critical variables, such as insight and therapeutic alliance. In contrast with this result, a recent systematic review assessing factors associated with nonadherence to antipsychotic treatment in bipolar disorder and schizophrenia ${ }^{61}$ did not identify attitude toward medication as a risk factor.

Medication side effects may be linked to attitude toward medication by affecting both the necessity and concern dimensions. Although cross-sectional studies showed a significant association between nonadherence and side effects, prospective studies suggest a more complex relationship likely reflecting 2 competing influences: the deterring impact of side effects versus willingness of patients to accept the discomfort of side effects in exchange for medication benefit. The balance between these influences is perhaps determined by patients' expectations of treatment and specific side effects. For example, weight gain attributed to treatment with antipsychotics may contribute to nonadherence among patients who perceive a negative effect on their body image but not among those who are indifferent to their weight status. ${ }^{45}$

Among the reasons for unintentional nonadherence, substance use or abuse was the only variable consistently found to contribute, regardless of type and stage of SMI. Current abuse of alcohol and/or illicit drugs ${ }^{12,32,34}$ and use of cannabis ${ }^{23,25}$ were strong independent predictors of future nonadherence. Of note, insight and attitude toward medication may not be powerful predictors of adherence for individuals with a history of substance abuse, as suggested by results from studies of patients with first-episode psychosis. ${ }^{30,32}$ Some patients may use recreational drugs or alcohol to self-manage symptoms of illness or to temporarily escape the stresses of a chronic health condition. Substance abuse is clearly a risk factor for poor adherence, and social and competence enhancement approaches targeting drug abuse in these individuals need to address the important issue of comorbidity. This review 
found that depressive symptoms may predict nonadherence for patients with schizophrenia, but the evidence is limited. Similarly, the relationship between adherence and some aspects of social functioning was assessed only in 3 studies, and the evidence regarding this complex variable is insufficient to evaluate its significance.

Lack of family/social support is another factor that may contribute to unintentional nonadherence. Positive family attitude to treatment and active family involvement in treatment of patients with schizophrenia were significantly associated with adherence; this effect may be indirect and possibly mediated by other variables, such as patient insight or attitude toward medication. Good social support for recovery from mental illness may be particularly important for adherence of patients who abuse substances, as suggested by results from a cross-sectional study that specifically examined reasons for nonadherence of patients with SMI and substance use disorder. ${ }^{42}$ Likewise, access to a mental health specialist, an indicator of good health care support, may be a variable affecting adherence, particularly for patients residing in geographic areas underserved by mental health care services, but the evidence assessed in this review is limited.

Patients with SMI often exhibit cognitive impairments ${ }^{62,63}$ that may hinder regular medication taking; however, results from the selected studies are inconsistent. Specific cognitive impairments interfering with the ability to manage medication may contribute to nonadherence, but the impact likely depends on other conditions and circumstances. For example, cognitive impairment may be a substantial obstacle for adherence among patients living independently or lacking good family support but not for those living with a family member involved in planning and monitoring medication intake. In addition, some impairments, such as forgetfulness and momentary distraction, may not be easily discovered using traditional cognitive testing and, therefore, may be underestimated as reasons affecting day-to-day medication adherence.

Chronicity of SMI may be an important factor in adherence, with nonadherence at early stages of illness being influenced by reasons that differ from those associated with long-term SMI. Although a direct comparison is difficult, results from studies in first-episode psychosis provide some direction. Negative initial interaction with staff members, involuntary admission, ${ }^{30}$ initial refusal to accept medication, ${ }^{26}$ use of cannabis during treatment, ${ }^{25}$ recent history of alcohol and drug misuse, ${ }^{32}$ perception of being overweight, ${ }^{45}$ and poor social support from family and friend ${ }^{26}$ may be reasons for nonadherence that are particularly potent in first-episode psychosis. Consistent with the findings of this review, a positive relationship with the treating physician has been identified as the major reason for adherence in patients with first-episode schizophrenia when compared with responses to the same questionnaire obtained from patients with multi-episode schizophrenia. ${ }^{64}$

\section{Limitations}

The inherent limitation of research on adherence is that only a subset of potential reasons can be assessed in parallel in each study. For example, a large prospective observational study of patients with schizophrenia that identified prior nonadherence, substance abuse, prior treatment with antidepressants, and greater medication-related cognitive impairments as the most significant predictors of nonadherence did not collect data on measures of attitude toward medication and therapeutic alliance and assessed insight only by using 1 item on the PANSS scale. ${ }^{34}$ Similarly, measures of attitude toward medication, insight, and therapeutic alliance were not included in another large prospective observational study of patients with schizophrenia that reported poor adherence at baseline, current alcohol dependence and substance abuse, independent living, and hostility at baseline as significant independent predictors of nonadherence. ${ }^{12}$ Because variables that are not measured may influence not only adherence but also the effects of measured variables on adherence, such uncontrolled confounding may lead to biased results and erroneous conclusions. Differences in study design (randomized controlled trial [RCT] versus observational) could also affect the results. Although RCTs provide a carefully controlled environment that ensures that the patient takes the medication as directed, routine care is better captured by observational studies.

Another major limitation of adherence research is the lack of an objective and reliable method of adherence measurement. The currently available objective methods, such as the Medication Event Monitoring System $\left(\mathrm{MEMS}^{\circledR}\right)$ bottle caps that capture pill container opening, pill counts, and pharmacy refill records, have limitations and provide only an estimate of patient adherence. ${ }^{65}$ Biologic assays that detect a drug or its metabolite in bodily fluids are rarely used because of the time-consuming and costly process that requires an office visit, invasive collection techniques, and laboratory analysis. The most commonly used modalities are subjective approaches relying on patient self-report or assessment provided by the HCP or caregiver ${ }^{66}$ that have low accuracy and tend to underestimate nonadherence. ${ }^{67}$ Despite these well-known limitations, 53\% (19/36) of studies selected for this review used a patient or HCP report as the only measure of adherence. Combining subjective measures from multiple sources (patient, HCP, and caregiver) with 
more objective modalities, such as pill counts or reviews of pharmacy records used in 36\% (13/36) of studies, may reduce although not eliminate bias. Only 2 studies used the MEMS, ${ }^{20,48}$ currently considered the gold standard for objective adherence assessment. Therefore, it is likely that nonadherence was underestimated in a large portion of the studies because a majority used unreliable adherence detection methods. In addition to differences in measuring adherence, there is substantial variability in adherence definitions and categories. Because the variable can be operationalized as dichotomous, categorical, or continuous, it is difficult to compare findings across studies. Furthermore, the inherently unstable nature of adherence over time complicates its prospective assessment. Taken together, the heterogeneity of research on adherence compromises the ability to compare results across individual studies.

It is important to note that none of the studies could conclusively establish causality of the analyzed associations. Prospective studies identified in this review provide a more robust data set with multiple assessments over time and thus a higher level of evidence relative to cross-sectional studies, but the findings remain associational because of the noninterventional design used in these studies.

The 11 categories of reasons for nonadherence identified in this systematic review likely represent at least a large majority of modifiable variables that contribute to this issue in patients with SMI. However, 2 limitations should be noted. First, some modifiable reasons for nonadherence that have appeared in the literature were not identified in this review. Examples include patient inability to pay for medication, ${ }^{68}$ logistic problems, and disorganized and chaotic living situation. ${ }^{69}$ Second, although the search aimed to identify articles related to schizophrenia, bipolar disorder, and MDD, a vast majority of articles included in the review report results from studies of patients with schizophreniaspectrum disorders, which limit generalization of findings to the other SMIs. In addition, conclusions regarding the factors affecting nonadherence to individual antipsychotics cannot be made because of interpatient variability in treatment response and tolerability.

\section{Conclusion}

Although there are methodologic limitations, reasons for antipsychotic drug nonadherence identified by studies conducted over the past decade seem to be relatively consistent. This review identified attitude toward medication and substance abuse as reasons most consistently linked with nonadherence in patients with SMI. Attitude toward medication is a complex and multidimensional variable that is related to both insight and therapeutic alliance. Substance abuse can serve as a relatively simple indicator of risk for nonadherence, and prevention programs targeting drug abuse should also focus on improving adherence. Although a negative attitude toward medication and use of substances should be a red flag for clinicians in identifying individuals at high risk for nonadherence, identifying the unique needs of each patient is a necessary step in designing appropriate individual intervention strategies to improve medication adherence.

\section{Acknowledgments}

This research was supported by ODH, Inc., Princeton, NJ. Writing and editorial assistance was provided by $\mathrm{C} 4$ MedSolutions, LLC (Yardley, PA), a CHC Group company, and funded by ODH, Inc. At the time of the literature search and analysis Ainslie Hatch and John Docherty were employees of Otsuka America Pharmaceutical, Inc. and Otsuka Pharmaceutical Development \& Commercialization, Inc. and are both currently employed by ODH, Inc.

\section{Disclosure}

Dawn I Velligan has received research support from Amgen and Otsuka; has been a consultant for Amgen, Forum, Otsuka, and Reckitt Benckiser; and has been a member of speaker bureaus for Janssen and Otsuka. Martha Sajatovic has received research support from the Centers for Disease Control and Prevention, Janssen, Merck, National Institutes of Health, Ortho-McNeil-Janssen, Pfizer, Reinberger Foundation, Reuter Foundation, and the Woodruff Foundation; has been a consultant for Bracket, Neurocrine, Otsuka, Pfizer, Prophase, and Sunovion; has received royalties from Johns Hopkins University Press, Lexicomp, Oxford University Press, Springer Press, and UpToDate; and has participated CME activities for the following organizations: American Physician Institute, CMEology, and MCM Education. Ainslie Hatch and John P Docherty are employees of ODH, Inc. Pavel Kramata was employed by C4 MedSolutions LLC at the time the research was conducted.

\section{References}

1. Leucht S, Tardy M, Komossa K, et al. Antipsychotic drugs versus placebo for relapse prevention in schizophrenia: a systematic review and meta-analysis. Lancet. 2012;379(9831):2063-2071.

2. Furukawa TA, Levine SZ, Tanaka S, et al. Initial severity of schizophrenia and efficacy of antipsychotics: participant-level meta-analysis of 6 placebo-controlled studies. JAMA Psychiatry. 2015;72(1):14-21.

3. Perlis RH, Welge JA, Vornik LA, Hirschfeld RM, Keck PE Jr. Atypical antipsychotics in the treatment of mania: a meta-analysis of randomized, placebo-controlled trials. J Clin Psychiatry. 2006;67(4):509-516. 
4. Nelson JC, Papakostas GI. Atypical antipsychotic augmentation in major depressive disorder: a meta-analysis of placebo-controlled randomized trials. Am J Psychiatry. 2009;166(9):980-991.

5. Spielmans GI, Berman MI, Linardatos E, Rosenlicht NZ, Perry A, Tsai AC. Adjunctive atypical antipsychotic treatment for major depressive disorder: a meta-analysis of depression, quality of life, and safety outcomes. PLoS Med. 2013;10(3):e1001403.

6. Thase ME, Youakim JM, Skuban A, et al. Efficacy and safety of adjunctive brexpiprazole $2 \mathrm{mg}$ in major depressive disorder: a phase 3, randomized, placebo-controlled study in patients with inadequate response to antidepressants. J Clin Psychiatry. 2015;76(9):1224-1231.

7. Lacro JP, Dunn LB, Dolder CR, Leckband SG, Jeste DV. Prevalence of and risk factors for medication nonadherence in patients with schizophrenia: a comprehensive review of recent literature. J Clin Psychiatry 2002;63(10):892-909.

8. Sajatovic M, Valenstein M, Blow FC, Ganoczy D, Ignacio RV. Treatment adherence with antipsychotic medications in bipolar disorder. Bipolar Disord. 2006;8(3):232-241.

9. Valenstein M, Ganoczy D, McCarthy JF, Myra Kim H, Lee TA, Blow FC. Antipsychotic adherence over time among patients receiving treatment for schizophrenia: a retrospective review. J Clin Psychiatry. 2006;67(10):1542-1550.

10. Weiden PJ, Kozma C, Grogg A, Locklear J. Partial compliance and risk of rehospitalization among California Medicaid patients with schizophrenia. Psychiatr Serv. 2004;55(8):886-891.

11. Ascher-Svanum H, Faries DE, Zhu B, Ernst FR, Swartz MS, Swanson JW. Medication adherence and long-term functional outcomes in the treatment of schizophrenia in usual care. J Clin Psychiatry. 2006; 67(3):453-460.

12. Novick D, Haro JM, Suarez D, Perez V, Dittmann RW, Haddad PM. Predictors and clinical consequences of non-adherence with antipsychotic medication in the outpatient treatment of schizophrenia. Psychiatry Res. 2010;176(2-3):109-113.

13. Hong J, Reed C, Novick D, Haro JM, Aguado J. Clinical and economic consequences of medication non-adherence in the treatment of patients with a manic/mixed episode of bipolar disorder: results from the European Mania in Bipolar Longitudinal Evaluation of Medication (EMBLEM) study. Psychiatry Res. 2011;190(1):110-114.

14. Velligan DI, Weiden PJ, Sajatovic M, et al. The expert consensus guideline series: adherence problems in patients with serious and persistent mental illness. J Clin Psychiatry. 2009;70 (Suppl 4):1-46; quiz 47-48.

15. Sajatovic M, Levin J, Tatsuoka C, et al. Six-month outcomes of customized adherence enhancement (CAE) therapy in bipolar disorder. Bipolar Disord. 2012;14(3):291-300.

16. Liberati A, Altman DG, Tetzlaff J, et al. The PRISMA statement for reporting systematic reviews and meta-analyses of studies that evaluate healthcare interventions: explanation and elaboration. BMJ. 2009;339:b2700.

17. Haddad PM, Brain C, Scott J. Nonadherence with antipsychotic medication in schizophrenia: challenges and management strategies. Patient Relat Outcome Meas. 2014;5:43-62.

18. Sendt KV, Tracy DK, Bhattacharyya S. A systematic review of factors influencing adherence to antipsychotic medication in schizophreniaspectrum disorders. Psychiatry Res. 2015;225(1-2):14-30.

19. Novick D, Montgomery W, Treuer T, Aguado J, Kraemer S, Haro JM. Relationship of insight with medication adherence and the impact on outcomes in patients with schizophrenia and bipolar disorder: results from a 1-year European outpatient observational study. BMC Psychiatry. 2015; 15:189.

20. Brain C, Allerby K, Sameby B, et al. Drug attitude and other predictors of medication adherence in schizophrenia: 12 months of electronic monitoring (MEMS((R))) in the Swedish COAST-study. Eur Neuropsychopharmacol. 2013;23(12):1754-1762.

21. Lam JW, Lui SS, Wang Y, Chan RC, Cheung EF. Prospective memory predicts medication management ability and correlates with non-adherence to medications in individuals with clinically stable schizophrenia. Schizophr Res. 2013;147(2-3):293-300.
22. Baloush-Kleinman V, Levine SZ, Roe D, Shnitt D, Weizman A, Poyurovsky M. Adherence to antipsychotic drug treatment in earlyepisode schizophrenia: a six-month naturalistic follow-up study. Schizophr Res. 2011;130(1-3):176-181.

23. Gonzalez-Pinto A, Reed C, Novick D, Bertsch J, Haro JM. Assessment of medication adherence in a cohort of patients with bipolar disorder. Pharmacopsychiatry. 2010;43(7):263-270.

24. Lepage M, Bodnar M, Joober R, Malla A. Is there an association between neurocognitive performance and medication adherence in first episode psychosis? Early Interv Psychiatry. 2010;4(2):189-195.

25. Miller R, Ream G, McCormack J, Gunduz-Bruce H, Sevy S, Robinson D. A prospective study of cannabis use as a risk factor for non-adherence and treatment dropout in first-episode schizophrenia. Schizophr Res. 2009;113(2-3):138-144.

26. Rabinovitch M, Bechard-Evans L, Schmitz N, Joober R, Malla A. Early predictors of nonadherence to antipsychotic therapy in first-episode psychosis. Can J Psychiatry. 2009;54(1):28-35.

27. Mohamed S, Rosenheck R, McEvoy J, Swartz M, Stroup S, Lieberman JA. Cross-sectional and longitudinal relationships between insight and attitudes toward medication and clinical outcomes in chronic schizophrenia. Schizophr Bull. 2009;35(2):336-346.

28. Morken G, Grawe RW, Widen JH. Effects of integrated treatment on antipsychotic medication adherence in a randomized trial in recent-onset schizophrenia. J Clin Psychiatry. 2007;68(4):566-571.

29. Liu-Seifert H, Adams DH, Ascher-Svanum H, Faries DE, Kinon BJ. Patient perception of medication benefit and early treatment discontinuation in a 1-year study of patients with schizophrenia. Patient Prefer Adherence. 2007;1:9-17.

30. de Haan L, van Amelsvoort T, Dingemans P, Linszen D. Risk factors for medication non-adherence in patients with first episode schizophrenia and related disorders; a prospective five year follow-up. Pharmacopsychiatry. 2007;40(6):264-268.

31. McEvoy JP, Johnson J, Perkins D, et al. Insight in first-episode psychosis. Psychol Med. 2006;36(10):1385-1393.

32. Kamali M, Kelly BD, Clarke M, et al. A prospective evaluation of adherence to medication in first episode schizophrenia. Eur Psychiatry. 2006;21(1):29-33.

33. Yamada K, Watanabe K, Nemoto N, et al. Prediction of medication noncompliance in outpatients with schizophrenia: 2-year follow-up study. Psychiatry Res. 2006;141(1):61-69.

34. Ascher-Svanum H, Zhu B, Faries D, Lacro JP, Dolder CR. A prospective study of risk factors for nonadherence with antipsychotic medication in the treatment of schizophrenia. J Clin Psychiatry. 2006; 67(7):1114-1123.

35. Eticha T, Teklu A, Ali D, Solomon G, Alemayehu A. Factors associated with medication adherence among patients with schizophrenia in Mekelle, Northern Ethiopia. PLoS One. 2015;10(3):e0120560.

36. Na E, Yim SJ, Lee JN, et al. Relationships among medication adherence, insight, and neurocognition in chronic schizophrenia. Psychiatry Clin Neurosci. 2015;69(5):298-304.

37. Jonsdottir H, Opjordsmoen S, Birkenaes AB, et al. Predictors of medication adherence in patients with schizophrenia and bipolar disorder. Acta Psychiatr Scand. 2013;127(1):23-33.

38. Dibonaventura M, Gabriel S, Dupclay L, Gupta S, Kim E. A patient perspective of the impact of medication side effects on adherence: results of a cross-sectional nationwide survey of patients with schizophrenia. BMC Psychiatry. 2012;12:20.

39. Alene M, Wiese MD, Angamo MT, Bajorek BV, Yesuf EA, Wabe NT. Adherence to medication for the treatment of psychosis: rates and risk factors in an Ethiopian population. BMC Clin Pharmacol. 2012;12:10.

40. Adelufosi AO, Adebowale TO, Abayomi O, Mosanya JT. Medication adherence and quality of life among Nigerian outpatients with schizophrenia. Gen Hosp Psychiatry. 2012;34(1):72-79.

41. McCabe R, Bullenkamp J, Hansson L, et al. The therapeutic relationship and adherence to antipsychotic medication in schizophrenia. PLoS One. 2012;7(4):e36080 
42. Magura S, Rosenblum A, Fong C. Factors associated with medication adherence among psychiatric outpatients at substance abuse risk. Open Addict J. 2011;4:58-64.

43. Sajatovic M, Levin J, Fuentes-Casiano E, Cassidy KA, Tatsuoka C, Jenkins JH. Illness experience and reasons for nonadherence among individuals with bipolar disorder who are poorly adherent with medication. Compr Psychiatry. 2011;52(3):280-287.

44. Zeber JE, Miller AL, Copeland LA, et al. Medication adherence, ethnicity, and the influence of multiple psychosocial and financial barriers. Adm Policy Ment Health. 2011;38(2):86-95.

45. Wong MM, Chen EY, Lui SS, Tso S. Medication adherence and subjective weight perception in patients with first-episode psychotic disorder. Clin Schizophr Relat Psychoses. 2011;5(3):135-141.

46. Beck EM, Cavelti M, Kvrgic S, Kleim B, Vauth R. Are we addressing the 'right stuff' to enhance adherence in schizophrenia? Understanding the role of insight and attitudes towards medication. Schizophr Res. 2011; 132(1):42-49.

47. Dassa D, Boyer L, Benoit M, Bourcet S, Raymondet P, Bottai T. Factors associated with medication non-adherence in patients suffering from schizophrenia: a cross-sectional study in a universal coverage healthcare system. Aust N Z J Psychiatry. 2010;44(10):921-928.

48. Acosta FJ, Bosch E, Sarmiento G, Juanes N, Caballero-Hidalgo A, Mayans T. Evaluation of noncompliance in schizophrenia patients using electronic monitoring (MEMS) and its relationship to sociodemographic, clinical and psychopathological variables. Schizophr Res. 2009;107(2-3):213-217.

49. Baldessarini RJ, Perry R, Pike J. Factors associated with treatment nonadherence among US bipolar disorder patients. Hum Psychopharmacol. 2008;23(2):95-105.

50. McCann TV, Boardman G, Clark E, Lu S. Risk profiles for nonadherence to antipsychotic medications. J Psychiatr Ment Health Nurs. 2008;15(8):622-629.

51. Rummel-Kluge C, Schuster T, Peters S, Kissling W. Partial compliance with antipsychotic medication is common in patients with schizophrenia. Aust N Z J Psychiatry. 2008;42(5):382-388.

52. Pratt SI, Mueser KT, Driscoll M, Wolfe R, Bartels SJ. Medication nonadherence in older people with serious mental illness: prevalence and correlates. Psychiatr Rehabil J. 2006;29(4):299-310.

53. Elbogen EB, Swanson JW, Swartz MS, Van Dorn R. Medication nonadherence and substance abuse in psychotic disorders: impact of depressive symptoms and social stability. J Nerv Ment Dis. 2005;193(10): 673-679.

54. Jonsdottir H, Opjordsmoen S, Birkenaes AB, et al. Predictors of medication adherence in patients with schizophrenia and bipolar disorder. Acta Psychiatr Scand. 2013;127(1):23-33.

55. Rummel-Kluge C, Schuster T, Peters S, Kissling W. Partial compliance with antipsychotic medication is common in patients with schizophrenia. Aust N Z J Psychiatry. 2008;42(5):382-388.
56. Weiden P, Rapkin B, Mott T, et al. Rating of medication influences (ROMI) scale in schizophrenia. Schizophr Bull. 1994;20(2):297-310.

57. Birchwood M, Smith J, Drury V, Healy J, Macmillan F, Slade M. A self-report Insight Scale for psychosis: reliability, validity and sensitivity to change. Acta Psychiatr Scand. 1994;89(1):62-67.

58. Hogan TP, Awad AG, Eastwood R. A self-report scale predictive of drug compliance in schizophrenics: reliability and discriminative validity. Psychol Med. 1983;13(1):177-183.

59. Switaj P, Wciorka J, Smolarska-Switaj J, Grygiel P. Extent and predictors of stigma experienced by patients with schizophrenia. Eur Psychiatry. 2009;24(8):513-520.

60. Day JC, Bentall RP, Roberts C, et al. Attitudes toward antipsychotic medication: the impact of clinical variables and relationships with health professionals. Arch Gen Psychiatry. 2005;62(7):717-724.

61. Garcia S, Martinez-Cengotitabengoa M, Lopez-Zurbano S, et al. Adherence to antipsychotic medication in bipolar disorder and schizophrenic patients: a systematic review. J Clin Psychopharmacol. 2016; 36(4):355-371

62. Vohringer PA, Barroilhet SA, Amerio A, et al. Cognitive impairment in bipolar disorder and schizophrenia: a systematic review. Front Psychiatry. 2013;4:87.

63. Bora E, Harrison BJ, Yucel M, Pantelis C. Cognitive impairment in euthymic major depressive disorder: a meta-analysis. Psychol Med. 2013; 43(10):2017-2026.

64. Sapra M, Weiden PJ, Schooler NR, Sunakawa-McMillan A, Uzenoff S, Burkholder P. Reasons for adherence and nonadherence: a pilot study comparing first- and multi-episode schizophrenia patients. Clin Schizophr Relat Psychoses. 2014;7(4):199-206.

65. Sajatovic M, Velligan DI, Weiden PJ, Valenstein MA, Ogedegbe G. Measurement of psychiatric treatment adherence. J Psychosom Res. 2010;69(6):591-599.

66. Velligan DI, Lam YW, Glahn DC, et al. Defining and assessing adherence to oral antipsychotics: a review of the literature. Schizophr Bull. 2006;32(4):724-742.

67. Byerly MJ, Thompson A, Carmody T, et al. Validity of electronically monitored medication adherence and conventional adherence measures in schizophrenia. Psychiatr Serv. 2007;58(6):844-847.

68. Zeber JE, Grazier KL, Valenstein M, Blow FC, Lantz PM. Effect of a medication copayment increase in veterans with schizophrenia. Am J Manag Care. 2007;13(6 Pt 2):335-346.

69. Velligan DI, Lam F, Ereshefsky L, Miller AL. Psychopharmacology: Perspectives on medication adherence and atypical antipsychotic medications. Psychiatr Serv. 2003;54(5):665-667.
Patient Preference and Adherence

\section{Publish your work in this journal}

Patient Preference and Adherence is an international, peer-reviewed, open access journal that focuses on the growing importance of patient preference and adherence throughout the therapeutic continuum. Patient satisfaction, acceptability, quality of life, compliance, persistence and their role in developing new therapeutic modalities and compounds to optimize

\section{Dovepress}

clinical outcomes for existing disease states are major areas of interest for the journal. This journal has been accepted for indexing on PubMed Central The manuscript management system is completely online and includes a very quick and fair peer-review system, which is all easy to use. Visit http://www. dovepress.com/testimonials.php to read real quotes from published authors. 